\title{
Scaling restoration of American lobsters: combined demographic and discounting model for an exploited species
}

\author{
Deborah P. French McCay ${ }^{1, *}$, Mark Gibson ${ }^{2}$, J. Stanley Cobb ${ }^{3}$ \\ ${ }^{1}$ Applied Science Associates, 70 Dean Knauss Drive, Narragansett, Rhode Island 02882, USA \\ ${ }^{2}$ Division of Fish and Wildlife, Rhode Island Department of Environmental Management, 3 Fort Wetherill Rd., \\ Jamestown, Rhode Island 02835, USA \\ ${ }^{3}$ Department of Biological Sciences, University of Rhode Island, Kingston, Rhode Island 02881, USA
}

\begin{abstract}
Ecological theory does not currently allow precise predictions of the consequences of ecological restoration. Ecological restoration and species enhancement projects could be profitably used to test theoretically based predictions, but only if theory were first applied to develop quantitative predictions suitable for testing. Here, we review what is known about factors limiting population size and production of the American lobster Homarus americanus, and use that information to construct a demographic life-table model of population dynamics. We then use the model to evaluate alternative options for enhancing lobster population size and production. Because this species represents an example of a population subjected to intense human exploitation as a target of commercial fisheries, which has stimulated much research on its biology, demographic modeling is facilitated. Furthermore, intervention into the fishery provides a viable restoration option available only to exploited species. We apply the economic concept of discounting (of future pay-back in the form of restoration, analogous to being paid interest on a loan) to allow quantification of the scale of restoration needed to compensate for both the magnitude of the estimated loss of American lobsters and the time lags between loss and restoration following a major oil spill. Quantification of benefits is rarely performed for restoration projects to guide compensation for natural resource damages caused by environmental incidents. The methods and approach developed here can help address this past failure in order to provide compensating ecological and human services equal to those lost. The approach represents a significant step forward in conceptually and quantitatively addressing restoration needs. The methods may be applied to other species, especially those that are exploited by humans, but also others that can feasibly be restored to mitigate impacts of adverse environmental events.
\end{abstract}

KEY WORDS: Restoration · American lobster · Population model $\cdot$ Limiting factor $\cdot$ North Cape oil spill $\cdot$ Fishery $\cdot$ Natural resource damage assessment $\cdot$ Interim loss

\section{INTRODUCTION}

Widespread degradation of coastal marine ecosystems and the goods and services that they provide (Jackson et al. 2001, Peterson \& Estes 2001) has stimulated great interest in the restoration of marine resources. Accordingly, restoration ecology has become perhaps the fastest-growing discipline in environmental sciences (Young 2000). Much of the practice of eco- logical restoration and species enhancement is organized by government resource agencies rather than by research scientists, yet these projects represent interventions into natural ecosystems that could be used effectively to test and improve the ecological theory required to achieve the intended restorations. For example, in the United States, when natural resources are impacted by environmental incidents, such as oil and chemical spills, pollutant releases, or physical 
destruction of habitat, federal and state agents ('trustees') are legally mandated to recover damages from responsible parties and to use those funds for restoration (NOAA 1997). The restoration should, by law, provide ecological and human services equivalent to those that were lost. In practice, however, many restoration projects have been pursued with only limited confidence that they might restore the intended level of services. Quantification of benefits is a particular challenge and is required to ensure that the scale of the restoration project compensates for the estimated magnitude of the injuries to the natural resources (i.e. provides ecosystem and human services equivalent in value to those lost).

Species restoration plans are based either upon restoration of habitat, which can have positive consequences for a wide suite of species, or upon ecological intervention designed for a particular species to relieve some population bottleneck that limits its abundance (Peterson et al. 2003, in this Theme Section). Speciesspecific interventions demand substantial, detailed information on the ecology of the species. Nevertheless, to restore a species of particular value (ecologically and/or economically), it may be preferable to focus on species-explicit restoration options, because such plans may provide more confidence that the target species will benefit. Species-explicit restoration projects manipulate one or more limiting factors to population growth. Recovery plans for endangered and threatened species (Clark et al. 2002) represent examples of restoration projects that commonly include species-explicit intervention projects. When the species to be enhanced is the target of a fishery or is otherwise exploited, that species may often be best restored by developing a species-specific set of manipulations. Typically, management agencies maintain databases on catch and often on effort, as well as conduct research on commercially important species, thus providing unusually detailed information needed to develop a quantitative understanding of factors limiting population size and growth. In addition, because marine fish stocks are so severely exploited (Pauly et al. 1998), management of fishing pressure to lower fishing mortality provides a viable means of modifying population size, and thus a highly predictable tool of effecting desired restoration in exploited species.

The American lobster Homarus americanus is clearly representative of an exploited species of sufficient economic value and ecological importance, as a top predator, to have stimulated substantial research on its basic biology. The lobster fishery is the most valuable commercial fishery of the Northeast United States (ASMFC 2000). In addition, the lobster is heavily exploited and reduced to population levels lower than those which would provide the maximum sustainable yield
(Fogarty \& Idoine 1988, ASMFC 2000). Thus, when an oil spill from the barge North Cape killed millions of lobsters in winter 1996, the responsible federal and state trustees developed a species-explicit plan for lobster restoration that considered manipulation of the fishery to compensate for the loss of the lobsters. This process of developing a quantitative model to guide lobster restoration serves as an example of how to advance restoration ecology in order to predict the quantitative benefits of restoration.

Here we describe the scientific bases for estimating the impact of the North Cape oil spill on the American lobster population along the Rhode Island (USA) coast, and for developing the restoration project that most reliably compensates for the loss. We first review the impact studies: estimated number of dead lobsters that washed ashore; use of field sampling to estimate impact by spatial and temporal contrasts of abundance of living lobsters; and ecotoxicological modeling of oil fates and the resulting acute mortality based on estimated pre-spill lobster abundance. We then review lobster life-history knowledge to identify factors that control population size and growth. For each of several potential restoration options based on known limiting factors, we use the population model to quantify the scale of the restoration required to match the lobster loss. Finally, we present the logical basis that led to the selection of the restoration choice deemed most feasible for the case and likely to be effective.

\section{ESTIMATING LOBSTER LOSSES}

On 19 and 20 January 1996, during a severe winter storm, the barge North Cape spilled 828000 gallons (3 134000 l) of home heating oil (No. 2 fuel oil) into the surf zone on the southern coast of Rhode Island, USA. Most of the oil was mixed into the water column by the heavy surf, resulting in high concentrations of toxic components (i.e. polynuclear aromatic hydrocarbons, PAHs) in the shallow waters near shore (French McCay 2003). Mortality of near-shore marine organisms quickly became evident in the form of large numbers of American lobsters, surf clams Spisula solidissima, other invertebrates, and fishes washed up dead on the beaches. Counting these lobster strandings during the first $12 \mathrm{~d}$ after the spill provided one means of estimating the numbers of lobsters lost (Gibson et al. 1997a). Because this estimate included only those dead lobsters that washed ashore, and therefore underestimated total mortality, a second field method was employed that involved sampling of the under-water habitats to assess the difference in lobster populations between impacted and control areas just after the spill (Cobb et al. 1999). 
A total of 18297 stranded lobsters were sexed and measured from transect and beach-sweep sampling to provide estimates of sex ratio (60\% female, $\mathrm{SE}=0.4 \%$ ) and size-frequency distribution of dead lobsters by $5 \mathrm{~mm}$ carapace length (CL) intervals (Gibson et al. 1997a). Total number of oil-impacted and stranded lobsters was estimated by sampling $2 \times 200 \mathrm{~m}$ transects parallel to the water line (along the deposition field of the last high-tide and including areas of high and low deposition and varying substrates) on each of 6 impact beaches, daily at low tide from 20 January to 2 February 1996 until new strandings had declined dramatically (to less than $10 \%$ of the minimum from any of the first $12 \mathrm{~d}$ ). The transects were subsampled daily at $25 \mathrm{~m}$ intervals with 5 randomly placed $1 \mathrm{~m}^{2}$ quadrats, with the width of the deposition zone estimated to enable expansion of the density data. After the quadrat-samples were taken, the entire $200 \mathrm{~m}$ beach section was swept clear of dead lobsters, and subsamples (by weight) of these sweep samples were sexed and sized. Sampling on control beaches (by sweeping the entire beach section clear due to very low incidence of lobster strandings) was also done to establish the relationship of the strandings to the spill. Daily mean quadrat densities of killed lobsters were estimated using a delta-distribution (Pennington 1983), due to the high frequency of null observations and the skewed distribution of the counts. Asymptotic mean quadrat density was estimated using a Weibull function applied to the cumulative daily means, to allow for additional strandings after the final day of sampling. The asymptotic quadrat densities were expanded to cover the entire beach area that accumulated stranded lobsters (area is estimated as impacted shoreline length times mean width of the depositional area), resulting in an estimate of 2.9 million dead lobsters stranded (Gibson et al. 1997a).

An estimate of the total kill of lobsters (9.0 million) was made by contrasting densities based on combined air-lift (<15 mm CL) and visual (>15 mm CL) samples conducted by divers soon after the spill in impacted and affected areas (Cobb et al. 1999). Side-scan sonar was used to map the boulder and cobble habitat that lobsters utilize within and nearby the area of the spill. The calculation of mortality involved assuming a prespill density of 1.76 lobsters $\mathrm{m}^{-2}$ (from Wahle \& Incze 1997) uniformly distributed over the rock and cobble reef area, developing a contour map of post-spill densities, and integrating numbers lost over the entire area where post-spill density was less than the assumed baseline (for a summary of the details of methods and calculations, see Cobb et al. 1999). This estimate of total lobster loss included a correction for $20 \%$ under-sampling of young-of-year (YOY: <15 mm $\mathrm{CL}$ ) derived from tests of the airlift gear sampling effi- ciency. Data from the beach strandings were used as the best estimate of size frequency of killed lobsters (Fig. 1). The strandings data underestimate YOY because these small lobsters are small and fragile and are likely to be lost or broken up in the surf. On the other hand, the strandings data provide a more reliable estimate of the size distribution of larger lobsters killed. The diver-conducted visual sampling from under water had a much smaller sample size, did not adequately capture the more mobile and evasive larger lobsters, and was done after the spill, so did not exactly match the dates of the mortality. If the ratio by number of YOY from airlift samples (corrected for $20 \%$ under-sampling) to lobsters $15-85 \mathrm{~mm}$ from visual density samples (i.e. from the pre-spill abundance distribution in Table 1) is used to correct the sizefrequency distribution of stranded lobsters, the size distribution of the kill would be slightly further skewed toward the smaller sizes (Fig. 1).

Lobster mortality was strongly skewed towards the smaller size classes (Table 1) in the estimates derived from sampling their habitat (Cobb et al. 1999). Only ca. 15000 of the 9.0 million total lost lobsters were adults (defined as $>85 \mathrm{~mm} \mathrm{CL}$ and $>5 \mathrm{yr}$ of age); the vast majority were juveniles, indicating the great

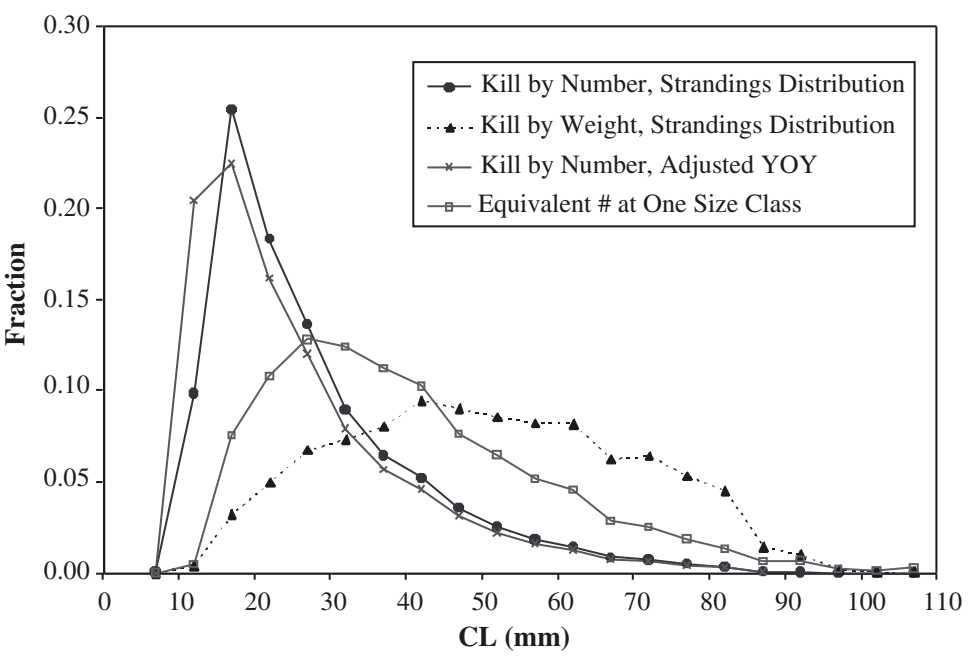

Fig. 1. Homarus americanus. Lobster mortality by size class for the North Cape oil spill. The size-frequency distribution of lobsters killed was based on measurements of 18297 killed lobsters collected from beach strandings after the spill. If \% young of year (YOY) is adjusted using the ratio of $<15 \mathrm{~mm}$ carapace length (CL) to $15-85 \mathrm{~mm}$ lobsters as the estimated pre-spill abundance size-distribution (Table 1), the size frequency distribution would be as indicated. The equivalent numbers at one (index) size class, which indicate the relative impacts by size, are calculated by multiplying (dividing) the number killed in a size class by the survival rate to (from) the index size class. The frequency distribution of the kill by weight is calculated by multiplying the numbers in each size class (based on the stranding-size distribution) by the wet weight per individual in that size class, derived from a length-weight relationship fit to data on Rhode Island lobsters 
Table 1. Homarus americanus. Estimated pre-spill abundance and kill by carapace-length size class (CL in $\mathrm{mm}$, midpoint of class) of the American lobster. The kill estimate was derived from comparisons of density inside and outside the spill area by air-lift and visual sampling soon after the spill (Cobb et al. 1999), combined with length and weight measurements of killed lobsters stranded after the spill

\begin{tabular}{|crrr|}
\hline CL $(\mathrm{mm})$ & Abundance (ind. $\left.\mathrm{m}^{-2}\right)$ & \multicolumn{1}{c|}{ Kill $(\#)$} & Kill $(\mathrm{kg})$ \\
\hline 7 & 0.0000 & 3436 & 1 \\
12 & 0.3600 & 889894 & 1491 \\
17 & 0.3953 & 2300217 & 10706 \\
22 & 0.2849 & 1657647 & 16438 \\
27 & 0.2119 & 1232654 & 22291 \\
32 & 0.1396 & 812380 & 24183 \\
37 & 0.1002 & 582972 & 26569 \\
42 & 0.0812 & 472614 & 31241 \\
47 & 0.0557 & 323872 & 29778 \\
52 & 0.0393 & 228510 & 28265 \\
57 & 0.0288 & 167335 & 27095 \\
62 & 0.0224 & 130147 & 26970 \\
67 & 0.0137 & 79468 & 20675 \\
72 & 0.0113 & 65975 & 21200 \\
77 & 0.0077 & 44985 & 17602 \\
82 & 0.0055 & 31788 & 14960 \\
87 & 0.0015 & 8696 & 4868 \\
92 & 0.0009 & 5099 & 3364 \\
97 & 0.0002 & 898 & 692 \\
102 & 0.0001 & 299 & 267 \\
107 & 0.0001 & 299 & 308 \\
Total & 1.7600 & 9039185 & 328963 \\
& & & \\
\hline
\end{tabular}

importance of these near-shore reef habitats of less than $10 \mathrm{~m}$ depth as lobster nurseries. Using a CL (mm)wet weight $(\mathrm{g})$ relationship $\left(W_{\mathrm{t}}=0.001143 \mathrm{CL}^{2.9337}\right)$ derived from measurements of the Rhode Island lobsters (see 'Growth rate' below), the estimated lobster losses were converted by class to biomass, producing an estimated loss of $329000 \mathrm{~kg}$ of lobsters, comprised mostly of small size classes (Table 1, Fig. 1).

In addition to field studies, ecotoxicological modeling of oil fates and resulting acute mortality was performed (French McCay 2003) to estimate injuries to marine organisms, including lobsters. A physical fates model was used to predict water column PAH concentrations, which were validated by field sampling. The estimate of lobster mortality from the model serves as an alternative means of estimating the numbers of lobsters killed by the spill, although it is not fully independent because it is based on the same pre-spill abundance of Wahle \& Incze (1997). The model produced an estimate of 8.3 million lobsters killed by the oil spill, consistent with that of 9.0 million based on airlift and visual quadrat sampling in the field. The quadrat- and modeling-based kill estimates are ca. 3 times the estimated number of stranded lobsters, which appears reasonable as many, but not all, killed lobsters would not have been washed up on beaches.

\section{DEVELOPMENT OF A DEMOGRAPHIC POPULATION MODEL}

To scale the size of the restoration project in units that would allow quantitative compensation for the lost lobsters and their services, we developed a model of lobster demography for the spill region. The model is size- and age-structured (using $5 \mathrm{~mm}$ CL intervals indexed in the center of the interval), and based on counting females, reflecting their value to reproduction (Ricker 1975). We first modeled individual growth rate to be able to develop the dynamics of size- and age-dependent reproduction and mortality from natural factors and from fishing. Finally these estimated schedules of growth, survivorship, and mortality were combined into a life table, which was used to compute demographically equivalent numbers of individuals at different life stages.

\section{Growth rate}

Lobster growth is a step function in which both the molt increment and frequency are functions of size (CL in $\mathrm{mm}$ ). The growth increment is generally modeled as a linear regression of post-molt $\left(\mathrm{CL}_{2}\right)$ on pre-molt length $\left(\mathrm{CL}_{1}\right)$ (Ennis 1980). A regression was developed (Gibson et al. 1997b) for Rhode Island inshore lobsters using paired pre- and post-molt length measurements on 123 lobsters (of both sexes) > 60 mm CL collected from 1990 to 1996 (Angell \& Lazar 1994, Angell 1995) and additional observations on smaller lobsters from Mauchline (1977), Hudon (1987), and James-Pirri (1996):

$$
\mathrm{CL}_{2}=1.744+1.094 \mathrm{CL}_{1}
$$

where the SEs of the slope and intercept were 0.005 and 2.106, respectively. Residuals by sex indicated a slight tendency to overestimate post-molt size in larger females. However, large females made up only a small percentage of the kill (Fig. 1).

Molt frequency is higher in smaller lobsters (Mauviot \& Castell 1976, Mauchline 1977, Fogarty \& Idoine 1988) and varies by sex for mature lobsters, as females extrude and carry eggs between molts, extending the intermolt period (ASMFC 2000). A logistic curve relating intermolt duration in years $\left(I_{\mathrm{d}}\right)$ to CL (Fogarty \& Idoine 1988) for mature female lobsters, from South of Cape Cod to Long Island Sound from the latest stock assessment report (ASMFC 2000), was used:

$$
\begin{gathered}
I_{\mathrm{d}}=\max (2, D) \text { or } \min (7, D) \\
\text { where } D=1+\mathrm{e}^{(-9.72+0.1032 \mathrm{CL})}
\end{gathered}
$$

The limits of 2 to $7 \mathrm{yr}$ serve to truncate the regression equation at the extremes, where the value of $D$ does 
not make biological sense. Whereas lobsters nearing maturity may molt annually, mature females molt, mate, wait a full year, and then extrude eggs. Thus, mature female lobsters generally have a minimum of a 2 yr molt cycle, although some small females in warmer waters may molt and spawn in the same summer. Tagging data indicate a maximum intermolt duration of ca. 7 yr (ASMFC 2000).

To depict lobster CL as a function of age (needed to estimate mortality), we used a rearrangement of the von Bertalanffy equation (a variation of the Brody growth equation: Ricker 1975):

$$
\left.\mathrm{CL}_{t}=\mathrm{CL}_{\infty}\left[1-\mathrm{e}^{\left(-\mathrm{K}\left(t-t_{0}\right)\right.}\right)\right]
$$

where $\mathrm{CL}_{t}$ is length (in $\mathrm{mm}$ ) at age $t_{1} \mathrm{CL}_{\infty}$ is the asymptotic maximum length, $\mathrm{K}$ is a constant called the Brody growth coefficient, and $t_{\mathrm{o}}$ is a constant. The value of $\mathrm{CL}_{\infty}(184.59 \mathrm{~mm})$ is a general northwest Atlantic value from Russell (1980). The values of $\mathrm{K}$ and $t_{\mathrm{o}}$ were fit to molt increment and timing data for inshore Rhode Island lobsters of $15 \mathrm{~mm} \mathrm{CL}: \mathrm{K}=0.135, t_{0}=-0.552$ (Gibson 1997b). As most Rhode Island lobsters are caught shortly after they enter the fishery at ca. $5 \mathrm{yr}$ of age, uncertainty in $\mathrm{CL}_{\infty}$ has little influence on the life-table results developed here. While a seasonal growth model (e.g. Hoenig \& Choudary Hanumara 1982, Pauly et al. 1992) might be used, the fit to local lobster size-at-age data allowed the computationally simpler annual model to be used in the present analysis, with little penalty in accuracy. To calculate weight from length:

$$
W_{t}=\mathrm{aCL}_{t}^{\mathrm{b}}
$$

where $W_{t}$ is wet weight $(\mathrm{g})$ at age $t \mathrm{yr}$, and a and $\mathrm{b}$ are constants, estimated as $\mathrm{a}=0.001143$ ( $\mathrm{SE}=0.3082$ of $\ln [\mathrm{a}]$ ) and $\mathrm{b}=2.9337$ (SE $=0.07347$ ) from measurements on 297 lobsters collected from Rhode Island Division of Fish and Wildlife research trawls.

\section{Reproductive rate}

The relationship between CL and the proportion of female lobsters that are mature can be described by a logistic function (Fogarty 1995). The necessary egg production data were obtained from ASMFC (2000) for lobsters in the region south of Cape Cod to Long Island Sound. The proportion of females that are ovigerous $\left(P_{\text {mat }}\right)$ and fecundity ( $f$ : eggs per clutch) as a function of $\mathrm{CL}$ are described by:

$$
\begin{gathered}
P_{\mathrm{mat}}=1 /\left[1+\mathrm{e}^{(18.145-0.249 \mathrm{CL})}\right] \\
f=0.000605 \mathrm{CL}^{3.7337}
\end{gathered}
$$

Whereas fecundity does not vary regionally among northwest Atlantic stocks, the fraction of smaller females that is ovigerous is higher in inshore southern New England than in the colder waters of the Gulf of Maine (Fogarty 1995). This geographic distinction has important implications for scaling restoration, because life-time egg production of newly-recruited southern New England lobsters is higher than it would be for similar-sized Gulf of Maine lobsters.

Mature female lobsters are assumed to produce eggs 1 or more times per molt cycle. ASMFC (2000) reports that lobsters > $120 \mathrm{~mm}$ CL spawn twice per molt cycle, and those $>200 \mathrm{~mm} \mathrm{CL}$ extrude eggs every 2 yr. Most females $<120 \mathrm{~mm}$ CL produce eggs once per molt cycle. Intense fishing pressure has removed almost all lobsters over $100 \mathrm{~mm} \mathrm{CL}$, so egg production from larger females is negligible.

\section{Natural and fishing mortality rates}

We adopted the basic fisheries population dynamics model of Ricker (1975). For lobsters of legal harvest size, the number at age $t(\mathrm{yr}), N_{t}$, is a function of the number of new recruits to the fishery at age $t_{\mathrm{r}}$ years. For $t \geq t_{\mathrm{r}}$ :

$$
\begin{gathered}
N_{t}=R \mathrm{e}^{-Z \mathrm{~A}\left(t-t_{\mathrm{r}}\right)} \\
Z_{\mathrm{A}}=M+F
\end{gathered}
$$

where $Z_{\mathrm{A}}$ is annual instantaneous total mortality (constant for ages $t>t_{\mathrm{r}}$ ), $M$ is annual instantaneous natural mortality, $F$ is annual instantaneous fishing mortality, and $R$ is the number of lobsters that first recruited in the cohort (i.e. $R=$ number at age $t_{\mathrm{r}}$ years). For $t \leq t_{\mathrm{r}}$ :

$$
N_{t}=N_{t-1} \mathrm{e}^{-Z_{t}}
$$

where $Z_{t}$ is the age-specific annual instantaneous natural mortality rate. The annual survival rate for age $t$ $\left(S_{t}\right)$ is thus:

$$
S_{t}=\mathrm{e}^{-\mathrm{Z}_{t}}
$$

Based on State of Rhode Island data (Gibson et al. 1997b) and federal stock assessments (NMFS 1996), we used the mean $F$ for the inshore Rhode Island lobster stock from 1992 to 1996 of 0.97 . The assumed instantaneous natural mortality rate of recruited (legalsized) lobsters, $M$, was set at 0.1 , which is the typical value used for northwest Atlantic lobster stocks (Bannister \& Addison 1986, Fogarty \& Idoine 1988). The legal CL limit for lobsters from 1996 to 1998 (when the injury calculations were made) was $82.6 \mathrm{~mm}$. The model assumes that lobsters fully recruit to the fishery at $82.6 \mathrm{~mm}$ (with $F=0$ and $M$ including handling mortality for discards of sublegals).

The mortality of lobsters $<82.6 \mathrm{~mm} \mathrm{CL}$ was estimated for 2 intervals:

$$
Z_{\mathrm{tot}}=Z_{\mathrm{e} 7}+Z_{\mathrm{juv}}
$$


where $Z_{\text {tot }}$ is the mortality from egg to $82.6 \mathrm{~mm} \mathrm{CL}, Z_{\mathrm{e} 7}$ is the mortality from egg to $7 \mathrm{~mm} \mathrm{CL}$, and $Z_{\text {juv }}$ is the mortality from 7 to $82.6 \mathrm{~mm} \mathrm{CL}$ (all instantaneous rates). Scaling of vital rates by body size is a general property of animal populations (Peters 1983, Dickie et al. 1987). Caddy (1986) suggested that natural mortality of lobsters is an inverse power-function of body size. His theoretical curve declined from $Z_{t}>1.0 \mathrm{yr}^{-1}$ for small lobsters to $M=0.1 \mathrm{yr}^{-1}$ for legal-sized lobsters. Wahle \& Steneck (1992) confirmed the declining vulnerability to predation with size. Thus, an empirical relationship of $Z_{t}$ to body size was developed for lobsters between $3 \mathrm{~mm}$ (larvae) and $82.6 \mathrm{~mm}$ (Gibson et al. 1997b). The data (Table 2) fit a linear relationship between $\ln \left(Z_{t}\right)$ and $\ln \left(W_{t}\right)$ in grams (Fig. 2):

$$
\ln \left(Z_{t}\right)=-0.627 \ln \left(W_{t}\right)-3.846
$$

Table 2. Homarus americanus. Estimates of lobster natural mortality rates $(M)$ at various life stages (EBP = early benthicphase lobsters). CL: carapace length; $\mathrm{CL}_{\infty}$ : asymptotic maximum length

\begin{tabular}{|c|c|c|c|c|}
\hline Stage & $\begin{array}{c}\mathrm{CL} \\
(\mathrm{mm})\end{array}$ & $\begin{array}{l}\text { Weight } \\
\text { (g) }\end{array}$ & $\begin{array}{c}M \\
\left(\mathrm{~d}^{-1}\right)\end{array}$ & Source \\
\hline Larvae I-III & 2.77 & 0.02 & 0.1234 & $\begin{array}{l}\text { Bibb \& Hersey } \\
\text { (1979) }\end{array}$ \\
\hline Larvae I-IV & 3.29 & 0.03 & 0.0984 & Stasko (1980) \\
\hline Larvae I-IV & 3.29 & 0.03 & 0.2400 & $\begin{array}{l}\text { Harding et al. } \\
\text { (1982) }\end{array}$ \\
\hline Larvae I-IV & 3.29 & 0.03 & 0.1253 & Scarratt (1964) \\
\hline Larvae I-IV & 3.29 & 0.03 & 0.1460 & $\begin{array}{l}\text { Hudon et al. } \\
\text { (1986) }\end{array}$ \\
\hline EBP 5-13 mm & 10 & 1.00 & 0.0394 & $\begin{array}{l}\text { James-Pirri } \\
\text { (1996) }\end{array}$ \\
\hline EBP $11-20$ & 16 & 3.64 & 0.0174 & $\begin{array}{l}\text { James-Pirri } \\
(1996)\end{array}$ \\
\hline EBP 5-25 mm & 15 & 3 & 0.0232 & Hudon (1987) \\
\hline EBP $25-60 \mathrm{~mm}$ & 40 & 55 & 0.0033 & Hudon (1987) \\
\hline EBP V- $70 \mathrm{~mm}$ & 37 & 44 & 0.0006 & $\begin{array}{l}\text { Harding et al. } \\
\text { (1982) }\end{array}$ \\
\hline EBP $13-85 \mathrm{~mm}$ & 49 & 100 & 0.0003 & $\begin{array}{l}\text { Bannister et al. } \\
\text { (1994) }\end{array}$ \\
\hline $\begin{array}{l}\text { EBP new } \\
\text { settlers, first } \\
\text { month }\end{array}$ & 13 & 2 & 0.0633 & $\begin{array}{l}\text { Wahle \& } \\
\text { Steneck } \\
(1992)\end{array}$ \\
\hline $\begin{array}{l}\text { Prerecruits, } \\
60-80 \mathrm{~mm}\end{array}$ & 70 & 284 & 0.0006 & $\begin{array}{l}\text { Angell (1995), } \\
60-80 \mathrm{~mm} \text { catch } \\
\text { curve slope }\end{array}$ \\
\hline $\begin{array}{l}\text { Large RI } \\
\text { adults, } \\
83-185 \mathrm{~mm}\end{array}$ & 134 & 1920 & 0.0002 & $\begin{array}{l}\text { Hoenig (1983) } \\
\text { longevity model } \\
\text { with a maximum } \\
\text { age of } 50 \mathrm{yr} \text { and } \\
\mathrm{CL}_{\infty}=185 \mathrm{~mm}\end{array}$ \\
\hline $\begin{array}{l}\text { Tagged legal } \\
\text { lobsters, RI } \\
\text { and MA }\end{array}$ & 90 & 595 & 0.0004 & Anthony (1980) \\
\hline
\end{tabular}

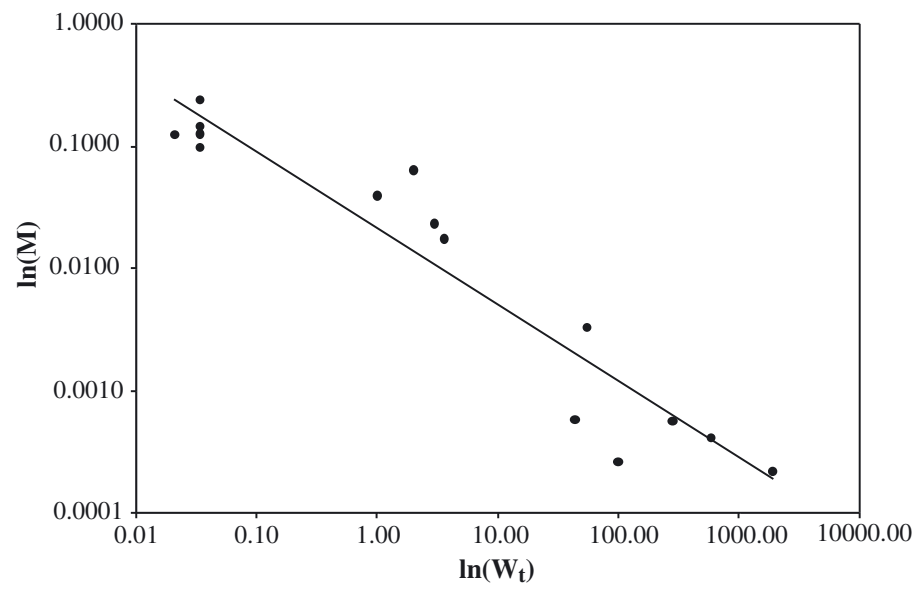

Fig. 2. Homarus americanus. Estimates of lobster natural mortality rates at various body weights, and regression line for log-transformed data

where $\mathrm{r}^{2}$ for the regression is 0.9078 ( $\mathrm{SE}=0.83, F=128$, 15 observations, $\mathrm{p}<0.05$ ) and the SEs of the slope and intercept are 0.0554 and 0.2241 , respectively. Translating body weight to $\mathrm{CL}$, daily mortality rates were estimated by size class. Age-at-size estimates using the von Bertalanffy equation provided duration for each $5 \mathrm{~mm}$ CL increment in the model, from which $Z$ for the increment was calculated (Table 3 ). The total mortality from 7 to $82 \mathrm{~mm} \mathrm{CL}\left(Z_{\text {juv }}\right)$ is 5.6 , based on the empirical mortality-rate curve.

The loss of eggs between extrusion and hatching was estimated by Perkins (1971) to be $36 \%$; thus, instantaneous egg mortality is ca. 0.45 (i.e. $64 \%$ of eggs hatch). The empirical mortality-rate curve implies $Z_{t}=0.147\left(\mathrm{~d}^{-1}\right)$ for the larval period (assumed $4 \mathrm{wk}$ ) and $Z_{t}=0.044\left(\mathrm{~d}^{-1}\right)$ from settlement to $7 \mathrm{~mm}(Z=1.33$ for the interval), giving a total $Z$ from hatching to $7 \mathrm{~mm}$ of 5.434 , inferring that $Z_{\mathrm{e} 7}=5.88(0.3 \%$ survival from egg to $7 \mathrm{~mm}$ ) and $Z_{\text {tot }}=11.5$. However, the larval mortality estimates based on field data (Table 2, Fig. 2) indicate daily mortality is ca. $0.1 \mathrm{~d}^{-1}$, or $Z=2.8$ for $28 \mathrm{~d}$ from hatch to settlement, implying $Z_{\mathrm{e} 7}=4.58$ ( $1 \%$ survival from egg to $7 \mathrm{~mm}$ ) and $Z_{\text {tot }}=10.2$. Thus, there is considerable uncertainty in $Z_{\mathrm{e} 7}$ and particularly in the mortality rate for the period between hatching and settlement.

\section{Life table}

To be able to compare the demographic value among age classes, and thereby compute such figures as the numbers of eggs equivalent to a given number of lobsters expected to recruit to the fishable population years later, we combined growth, mortality, and 
Table 3. Homarus americanus. Estimated age and total instantaneous mortality rate ( $Z$, from Gibson et al. 1997b) by carapace-length (CL) size class for American lobster. Age is calculated from length using a rearrangement of the von Bertalanffy growth equation fit to local lobster size-at-age data. Survival is calculated as $\mathrm{e}^{-Z_{7, i}, \text { where }} Z_{7, i}$ is the summed mortality rate from $7 \mathrm{~mm}$ to size class $i$

\begin{tabular}{|cccc|}
\hline CL $(\mathrm{mm})$ & Age (yr) & $\begin{array}{c}Z \text { to next size } \\
\text { Class (in } \\
\text { increments } \\
\text { of } 5 \text { mm) }\end{array}$ & $\begin{array}{c}\text { Survival } \\
\text { from } \\
7 \text { mm to } \\
\text { size class }\end{array}$ \\
\hline 7 & & 2.172 & 1.0000 \\
12 & 0.84 & 1.006 & 0.1140 \\
17 & 1.05 & 0.589 & 0.0417 \\
22 & 1.27 & 0.393 & 0.0231 \\
27 & 1.49 & 0.285 & 0.0156 \\
32 & 1.72 & 0.219 & 0.0117 \\
37 & 1.96 & 0.175 & 0.0094 \\
42 & 2.21 & 0.145 & 0.0079 \\
47 & 2.46 & 0.123 & 0.0068 \\
52 & 2.73 & 0.106 & 0.0061 \\
57 & 3.00 & 0.094 & 0.0054 \\
62 & 3.29 & 0.084 & 0.0050 \\
67 & 3.58 & 0.076 & 0.0046 \\
72 & 3.89 & 0.070 & 0.0042 \\
77 & 4.21 & 0.065 & 0.0039 \\
82 & 4.55 & 0.359 & 0.0037 \\
87 & 4.90 & 0.378 & 0.0026 \\
92 & 5.27 & 0.399 & 0.0018 \\
97 & 5.66 & 0.422 & 0.0012 \\
102 & 6.07 & 0.449 & 0.0008 \\
107 & 6.51 & 0.479 & 0.0005 \\
& 6.97 & & \\
\hline & & & \\
\hline & & & \\
\hline
\end{tabular}

reproduction relationships into a life table for the affected population (Table 4). The expected annual production of eggs per female of age class $X$ in the population $\left(M_{X}\right)$ was calculated from $P_{\text {mat }}, f$, and the proportion of females in the population that produces eggs during a given year $\left(P_{\mathrm{e}}\right)$. We derive $P_{\mathrm{e}}$ from $I_{\mathrm{d}}$ in years and the number of clutches produced per molt cycle $\left(C_{\mathrm{m}}\right)$ :

$$
\begin{gathered}
M_{X}=P_{\text {mat }} f P_{\mathrm{e}} \\
P_{\mathrm{e}}=C_{\mathrm{m}} / I_{\mathrm{d}}
\end{gathered}
$$

Our maturation equation implies that very young females produce eggs. However, we assumed that eggs are not produced by lobsters younger than 4 yr of age $(67 \mathrm{~mm})$. In southern New England, lobsters carry eggs for 10 to 11 mo before release, during which time they do not molt (Cobb et al. 1997). Thus, once lobsters mate and produce eggs, they begin a 2 yr molt cycle (ASMFC 2000). The intermolt duration in the life table reflects the molt cycles of egg-producing lobsters.

Table 4 presents expected lifetime egg production (LEP) per female of each size/age class, calculated for age $X$, as:

$$
\mathrm{LEP}_{X}=\frac{\left[\sum_{\mathrm{n}=X}^{\mathrm{n}=X \max }\left(\mathrm{LX}_{\mathrm{n}} M X_{\mathrm{n}}\right)\right]}{\mathrm{LX}_{X}}
$$

where $\mathrm{n}$ is age in years (evaluated in the summation from age $X$ to the maximum age $\left.X_{\max }\right), \mathrm{LX}_{\mathrm{n}}$ is the frac-

Table 4. Homarus americanus. Life table estimating lifetime egg production per female lobster of age $X$ (yr). CL: carapace length in $\mathrm{mm}_{;} P_{\mathrm{mat}}$ : fraction ovigerous; $f$ : fecundity (eggs per clutch); $I_{\mathrm{d}}$ : intermolt duration $(\mathrm{yr}) ; C_{\mathrm{m}}$ : number of clutches per molt cycle;

\begin{tabular}{|c|c|c|c|c|c|c|c|c|c|c|c|c|}
\hline$X$ & CL & $P_{\text {mat }}$ & $f$ & $I_{\mathrm{d}}$ & $C_{\mathrm{m}}$ & $P_{\mathrm{e}}$ & $M_{X}$ & $S_{X}$ & $L X$ & $L X M_{X}$ & $X L X M_{X}$ & LEP \\
\hline 0.8 & 7 & 0.00 & 1 & 1 & 0 & 0.00 & - & 0.114 & $1.00 \mathrm{E}+00$ & 0 & 0 & 30 \\
\hline 1.0 & 12 & 0.00 & 6 & 1 & 0 & 0.00 & - & 0.103 & $1.14 \mathrm{E}-01$ & 0 & 0 & 266 \\
\hline 2.0 & 32 & 0.00 & 243 & 1 & 0 & 0.00 & - & 0.516 & $1.17 \mathrm{E}-02$ & 0 & 0 & 2584 \\
\hline 3.0 & 52 & 0.01 & 1479 & 1 & 0 & 0.00 & - & 0.753 & $6.06 \mathrm{E}-03$ & 0 & 0 & 5007 \\
\hline 3.9 & 67 & 0.19 & 3799 & 2 & 1 & 0.50 & 357 & 0.810 & $4.56 \mathrm{E}-03$ & 1.63 & 6.34 & 6652 \\
\hline 4.9 & 82 & 0.91 & 8060 & 2 & 1 & 0.50 & 3653 & 0.379 & 3.69E-03 & 13.49 & 66.12 & 7773 \\
\hline 6 & 96 & 1.00 & 14561 & 2 & 1 & 0.45 & 6536 & 0.379 & $0.00 \mathrm{E}+00$ & 9.146 & 54.88 & 10868 \\
\hline 7 & 107 & 1.00 & 21926 & 5 & 1 & 0.21 & 4504 & 0.379 & $0.00 \mathrm{E}+00$ & 2.389 & 16.72 & 11427 \\
\hline 8 & 117 & 1.00 & 30321 & 7 & 2 & 0.29 & 8663 & 0.379 & $0.00 \mathrm{E}+00$ & 1.742 & 13.94 & 18263 \\
\hline 9 & 126 & 1.00 & 39395 & 7 & 2 & 0.29 & 11256 & 0.379 & $1.40 \mathrm{E}-03$ & 0.8580 & 7.72 & 25326 \\
\hline 10 & 133 & 1.00 & 48825 & 7 & 3 & 0.43 & 20925 & 0.379 & $5.30 \mathrm{E}-04$ & 0.6047 & 6.05 & 37116 \\
\hline 11 & 140 & 1.00 & 58329 & 7 & 3 & 0.43 & 24998 & 0.379 & $2.01 \mathrm{E}-04$ & 0.27384 & 3.01 & 42711 \\
\hline 12 & 145 & 1.00 & 67684 & 7 & 3 & 0.43 & 29007 & 0.379 & $7.62 \mathrm{E}-05$ & 0.12046 & 1.45 & 46724 \\
\hline 13 & 150 & 1.00 & 76716 & 7 & 3 & 0.43 & 32878 & 0.379 & $2.89 \mathrm{E}-05$ & 0.05176 & 0.673 & 46737 \\
\hline 14 & 155 & 1.00 & 85303 & 7 & 3 & 0.43 & 36558 & 0.379 & $1.10 \mathrm{E}-05$ & 0.02182 & 0.305 & 36558 \\
\hline \multirow{3}{*}{\multicolumn{10}{|c|}{$\begin{array}{l}\text { Total }=\# \text { of } 7 \mathrm{~mm} \text { offspring per } 7 \mathrm{~mm} \mathrm{CL} \text { female }=\mathrm{RO}=\sum\left(L X M_{X}\right) \\
\text { Required survival from egg to } 7 \mathrm{~mm} \mathrm{CL}\left(S_{\mathrm{e} 7}\right) \text { for equilibrium }=2 / \mathrm{RO}= \\
\text { Generation time }(\mathrm{yr})=\left[\sum\left(X L X M_{X}\right)\right] / \mathrm{RO}\end{array}$}} & 30.3 & \multirow{3}{*}{\multicolumn{2}{|c|}{5.8}} \\
\hline & & & & & & & & & & 0.066 & & \\
\hline & & & & & & & & & & & & \\
\hline
\end{tabular}
$P_{\mathrm{e}}$ : proportion of females in the population that are egg-bearing; $M_{X}$ : eggs per female of age $X$ in the population; $S_{X}$ : survival rate at age $X_{i} L X$ : survivorship from age 0.8 to age $X_{i}$ LEP: lifetime egg production for age $X$ 
tion surviving to age $\mathrm{n}$, and $M X_{\mathrm{n}}$ is the egg production at age $\mathrm{n}$. For example, the lifetime production expected from a $7 \mathrm{~mm}$ female (RO) just settling to the benthic habitat is 30.3 eggs. The lifetime fecundity $\left(F_{\mathrm{a}}\right)$ of an $82 \mathrm{~mm}$ female is estimated as 7773. Although larger, legally fishable females produce large numbers of eggs, few survive beyond $96 \mathrm{~mm} \mathrm{CL}$, making their contribution to the next generation insignificant. The generation time is $5.8 \mathrm{yr}$ (calculated as: $\sum X \mathrm{LX} M X$ / $\mathrm{RO}$ ).

If it is assumed that the population (with the survival schedule in Table 4) is in equilibrium, such that a $7 \mathrm{~mm}$ lobster would just exactly replace herself plus 1 male after a lifetime of egg production, survival from egg to $7 \mathrm{~mm}$ is estimated as $6.6 \%$ (i.e. $2 / \mathrm{RO}=2 / 30.3$ ), implying that $Z_{\mathrm{e} 7}=2.72$. This equilibrium survival estimate is much higher than the empirical data indicate (i.e. 0.3 to $1.0 \%$ survival from egg to $7 \mathrm{~mm}, S_{\mathrm{e} 7}$ ). If $S_{\mathrm{e} 7}$ is 0.3 to $1.0 \%$, in order for the population to sustain itself at the exploitation rate implied by $F=1$, the lifetime eggproduction of a $7 \mathrm{~mm}$ female would need to be 192 to 716 eggs. It has been suggested that the Rhode Island inshore population cannot sustain itself (based on similar analyses of survival rates and lifetime fecundity) and is supplemented by larval supply from offshore (Katz et al. 1994, Fogarty 1998), and this discrepancy between the empirical and equilibrium estimates indicates a very large offshore supplement. Annual (instantaneous) mortality of $>82.6 \mathrm{~mm}$ lobsters would need to decrease to $Z=0.22$ for the inshore population to be self-sustaining, assuming $S_{\mathrm{e} 7}$ is $1 \%$ and the survival schedule in Table 3. Alternatively, if survival to $82.6 \mathrm{~mm}$ is underestimated, lifetime egg production of a $7 \mathrm{~mm}$ female would be higher, perhaps high enough to be self-sustaining in the inshore area. Clearly, further data collection and analysis is needed to resolve the survival rates of $<82.6 \mathrm{~mm}$ lobsters.

From an age-specific survival schedule, one can calculate how many lobsters of any given age are demographically equivalent to a number at any other age. This type of conversion is important in creating a restoration plan that achieves quantitative equivalence of lost and restored lobster numbers, because precise matching of age distributions will generally be impossible. This approach (typically with losses translated to equivalent adults) has been used for power plant impingement and entrainment assessments (following suggestion by Horst 1975, Goodyear 1977) and mitigation of dredging impacts (Wainwright et al. 1992, Dumbauld et al. 1993).

We compute (Table 5) the numbers of lobsters in each class that would be required by the mortality schedule in Table 3 to yield numbers of newly recruited lobsters (82.6 $\mathrm{mm} \mathrm{CL}$ ) equivalent to the total kill estimate (i.e. 'equivalent adults'). The total loss of 9 million lobsters distributed among sizes, as in Table 1, is equivalent to the loss of 2.2 million new recruits from the legally fishable population (Table 5). Similarly, calculating backwards through the life stages, the observed kill translates into 608 million $7 \mathrm{~mm}$ lobsters (Table 5). We converted the equivalent numbers at $82.6 \mathrm{~mm}$ CL to fractions of the total recruit equivalents (Fig. 1), which shows that the greatest demographic impact of the oil spill was suffered by the second year class of juveniles (1.5 to 2 yr old), with a median CL of $27 \mathrm{~mm}$. Note that the proportional distribution of demographic equivalents by size class is the same, regardless of the size class used as the basis of the calculations. Thus, this procedure normalizes the loss to a single unit of equivalent population value.

To proceed further backwards in the life history to estimate the number of egg equivalents, we used the estimated survival from egg to $7 \mathrm{~mm}\left(S_{\mathrm{e} 7}\right)$ of: (1) 0.3 to $1 \%$ based on analysis of empirical data, and (2) $6.6 \%$ inferred by the life table for female lobsters, assuming equilibrium such that the inshore population is selfsustaining (Table 4). The number of lobsters killed in the spill originated from 59 to 219 billion eggs, assuming the empirical survival rates $\left(S_{\mathrm{e} 7}=1\right.$ or $0.3 \%$, respectively), and 9.2 billion eggs, assuming the life table and equilibrium $\left(\mathrm{S}_{\mathrm{e} 7}=6.6 \%\right.$, Table 5$)$. Thus, there is great uncertainty in the number of egg equivalents lost, reflecting the uncertainty in egg to $7 \mathrm{~mm}$ survival.

\section{LIMITATION OF LOBSTER POPULATION SIZE AND PRODUCTION}

For restoration to be effective, the selected project(s) must increase the local lobster population at a scale that will provide augmented production to compen-

Table 5. Homarus americanus. Lobster loss from the North Cape oil spill in 1996 using age-specific survivorships converted into the demographic equivalents for each of several size classes. $\mathrm{S}_{\mathrm{e} 7}$ : survival from egg to $7 \mathrm{~mm}$ carapace length (CL)

\begin{tabular}{|lccc|}
\hline $\begin{array}{l}\text { Equivalent \# } \\
\text { at Stage }\end{array}$ & Total & Females & Males \\
\hline $82.6 \mathrm{~mm}$ & 2228402 & 1337041 & 891361 \\
$22 \mathrm{~mm}$ & 14046329 & 8427797 & 5618531 \\
$7 \mathrm{~mm}$ (millions) & 608 & 365 & 243 \\
$\begin{array}{l}\text { Postlarvae } \\
\text { (millions) }\end{array}$ & 7217 & 4330 & 2887 \\
$\begin{array}{l}\text { Eggs (millions), } \\
\text { empirical }\end{array}$ & 58940 & 35364 & 23576 \\
$\begin{array}{l}\left.\text { (S } \mathrm{S}_{\mathrm{e}}=1 \%\right) \\
\text { Eggs (millions), }\end{array}$ & 9211 & 5527 & \\
equilibrium & & & \\
(S $\left.\mathrm{e}_{\mathrm{e}}=6.6 \%\right)$ & & & \\
\hline
\end{tabular}


sate for loss of production. Consequently, restoration planning begins with identifying the factors that limit population size and productivity. Population size for any given species is unlikely to be limited by a single factor, unless a strong density-dependent bottleneck exists at some particular life stage. Different life stages are commonly controlled by different factors. In exploited marine fish and shellfish, over-harvesting generally has taken place to limit abundances in the larger size and age classes subject to fishing pressure (Pauly et al. 1998). Limiting factors can vary by location. For example, Lipcius et al. (1997) provide evidence that habitat availability limits recruitment of the spiny lobster Panulirus argus in some areas, while larval supply is limiting for other parts of the Bahamas. Evidence that may suggest habitat limitation for American lobsters comes from artificial reefs, which are quickly colonized by larger American lobsters (Scarratt 1968, Sheehy 1976, Castro et al. 2001), and YOY settlement increased when cobble habitat was provided in a formerly muddy area (Castro et al. 2001). Habitat availability, fishing pressure, and larval supply seem likely candidates as limiting factors for American lobster populations.

The literature on the biology of the American lobster characterizes its life history and ecological importance reasonably well. It has a long period of parental care and a short larval life (Cobb et al. 1997). Eggs are carried by the females for 9 to 12 mo before being released at hatching. Resulting larvae are planktonic, remaining in the water column for ca. 1 mo before settling to the bottom as postlarvae (Ennis 1995). Young juveniles (10 to $25 \mathrm{~mm} \mathrm{CL}$ ) seek shelter, usually in rocky cobbles and boulders, and remain secluded, feeding from within the shelter (Wahle \& Steneck 1991). Older juveniles leave the shelter for feeding forays, but return frequently. As lobsters grow larger, they may leave shelters and move greater distances (Lawton \& Lavalli 1995). These characteristics imply strong predatory control on early life-history stages, and indicate the dependence of at least early benthic stages on shelter (Wahle \& Steneck 1991, 1992). However, the lower dependence of larger lobsters on shelters and high fishing rates (NMFS 1996) suggest that fishing limits population size in the larger size classes, possibly to the extent that larval supply is limiting to recruitment.

\section{Habitat availability and juvenile survival}

Inshore populations of juvenile and adult lobsters utilize cobble, rock, peat reefs and kelp beds, where the structure of the habitat provides shelter (Cobb 1971) and foraging habitat. Population densities in- crease when artificial shelters are placed in the field (Scarratt 1968, Sheehy 1976, Lawton \& Lavalli 1995, Castro et al. 2001). Lobsters are preyed upon by many bottom-feeding fish species, and addition of shelter likely reduces predation losses. Lobsters are omnivorous, acting mainly as predators, but also as scavengers (Herrick 1909, MacKenzie \& Moring 1985, Hudon \& Lamarche 1989, Lawton \& Lavalli 1995). Calculations of prey production rates by Miller et al. (1971) suggest that lobster populations are not likely to be limited by food.

There have been many suggestions that the early benthic phase $(\mathrm{EBP} ; \sim 5$ to $40 \mathrm{~mm} \mathrm{CL})$ is structuredependent and may act as a recruitment bottleneck to the fishable stock (Caddy 1986, Fogarty \& Idoine 1986, Hudon 1987, Able et al. 1988, Wahle \& Steneck 1991, 1992, Miller et al. 1992, Fogarty 1995, Lawton \& Lavalli 1995). The availability of physical structures that provide refuge from predation affects survival rates of several crustaceans, resulting in increased densities in those habitats (Wahle \& Steneck 1991, 1992, Dumbauld et al. 1993, Beck 1995, 1997). Wahle (1993) censused lobsters along $22 \mathrm{~km}$ within Narragansett Bay, finding that newly settled lobsters were absent from the prevailing sedimentary bottoms, which lack emergent structure and associated refuges, suggesting that structured habitat might be in short supply in Rhode Island waters. Wahle \& Steneck (1991) similarly proposed that cobble habitats are preferred by the early benthic stages and limit population size. The potential for habitat limitation in early life history is also suggested by the study by Castro et al. (2001), who showed that when cobble reefs were placed in a muddy area, settlement of YOY lobsters increased from none to the equivalent of natural settlement in nearby rocky areas. However, Wahle \& Inze (1997) ruled out habitat differences and implicated larval supply as being the mechanism behind the difference in recruitment on 2 sides of an island. They found that emigration by larger juveniles probably controlled the population size, suggesting that habitat limitation plays a role as body size increases. These studies, and those showing the effectiveness of addition of artificial habitat in enhancing lobster local abundance (Scarratt 1968, Sheehy 1976, Lawton \& Lavalli 1995), suggest that an increase in cobble reef habitat in inshore waters of Rhode Island may enhance juvenile survival and increase local lobster populations.

\section{Fishing mortality}

Lobster stocks of the northwest Atlantic are known to be highly exploited (Fogarty \& Idoine 1988, NMFS 1996, ASMFC 2000). The fishing mortality rate on 
inshore Rhode Island lobsters is estimated at or above sustainable levels (Gibson et al. 1997b), with $F=1$ for the inshore population in the 1990s. Fogarty (1995) provided even higher estimates of $F$ for southern New England and northeast USA stocks in general for previous years. From our life table (Table 4), it is clear that females that survive for more than 1 to 2 molt cycles after reaching fishable age and size contribute little egg production to the population. Thus, the population is dependent on egg production from smaller females and possibly on larval subsidy from offshore adults (Fogarty 1998). This implies that fishing pressure limits lobster population size, which in turn controls egg production. It follows that reduction in fishing mortality would increase adult population size and production, with enhancement of the next generation through increased egg production.

\section{Egg production and postlarval supply}

Lobster management in the United States is based on egg production per recruit, on the assumption that populations are limited by egg production and resulting larval supply due to very high levels of exploitation on adult females (Fogarty \& Idoine 1988, NMFS 1996). The relationship between stock size and recruitment has not been examined for Homarus americanus. However, the relationship between larval production and stock size and/or landings has been evaluated in detail (Fogarty 1995). Fogarty \& Idoine (1986), using data for Northumberland Strait, concluded that the relationship was asymptotic, with a clear indication of density dependence. The relationship has a steep slope near the origin, indicating that larval supply may be limiting at low stock size, but at higher stock sizes there is some density-dependent control on the population, such as intraspecific competition for food or shelter resources (Fogarty 1995). Wahle \& Incze (1997) present evidence that postlarval supply, determined by local hydrodynamic conditions, can limit settlement density of lobsters in cobble habitats. However, they suggest that as lobsters grow, crowding arises, causing emigration and smoothing annual variation in lobster density patterns, caused by differences in larval supply.

Benthic settlement is highly variable spatially and from year to year. Incze et al. (1997) found that postlarval supply and benthic settler density were significantly correlated in data sets from Rhode Island and Maine waters from 1989 to 1995. Postlarval supply explained $90 \%$ of the annual variation in settler density for the combined data set. Among-site differences in recruitment persisted for $1 \mathrm{yr}$ after settlement, after which larger lobsters moved into areas of initially lower settlement. This implies that larval supply may be limiting to settlement, but that subsequently habitat becomes limiting. Incze et al. (2000) showed that YOY recruitment was positively correlated with larval supply at a single site in Maine, and suggested that density-dependent effects may have been operating at times when recruitment was highest.

Thus, habitat availability, fishing pressure, and larval supply appear to be limiting to American lobster populations in southern New England via control on different life stages. However, given the very high fishing pressure and recent precipitous decline in the Rhode Island stock and catch (indicated by Rhode Island Division of Fish and Wildlife research trawl data and catch statistics from recent years), it seems clear that adult stocks are limited by fishing. The degree of limitation by larval supply and habitat for early benthic stages is much less certain. Thus, the choice of an appropriate restoration approach in this case was a matter of judgment based on uncertain outcomes and logistical constraints.

\section{ALTERNATIVES FOR LOBSTER RESTORATION}

\section{Stocking with juveniles raised in hatcheries}

If lobster populations are limited, in part, by larval supply, then rearing lobsters in a hatchery through to settlement size, and releasing them into nature, represents one restoration option. The techniques for rearing lobsters to the postlarval stage at a size suitable for release are well established, and lobster enhancement through this process has been performed many times (Addison \& Bannister 1994). Unfortunately, no project has documented the stocking success of hatcheryreared Homarus americanus, primarily because of limitations in the collection tracking and monitoring data (Bannister \& Addison 1998, Castro et al. 2001). Success has been evaluated in Europe with Homarus gammarus (Bannister et al. 1994, Phillips \& Evans 1997), but the applicability of these results to the congeneric lobster in Rhode Island waters is questionable. Castro et al. (2001) stocked micro-wire tagged YOY lobsters directly onto artificial reefs in Rhode Island, but no increase in density over natural settlement of YOY was detected, and only one tagged individual was ever recovered. The authors suggested that hatchery-reared lobsters may be more susceptible to predation than naturally produced juveniles, based upon the lack of immediate shelter-seeking behavior upon release of hatcheryderived lobsters. This problem of abnormal behavior and high susceptibility to predation is common among other animals reared in captivity (Olla et al. 1998).

Even if hatchery-reared lobsters were to survive introduction into the wild, this restoration option car- 
ries some other risks common to hatchery-based stock enhancement. The introduced lobsters may compete with naturally produced individuals, introduce disease from the hatchery, or induce undesirable genetic changes in the native stock. The hatchery-raised lobsters may interact in some unnatural and undesirable fashion with the receiving ecosystem. Whereas analogous concerns have been exemplified in salmon stocks, they are less likely to be a problem in American lobsters, since the native populations are not at similarly depleted levels where the risks would be magnified. Nevertheless, hatchery stocking of Homarus americanus has not yet been demonstrated as a successful restoration strategy, so there is substantial uncertainty associated with this option.

\section{Habitat (rock reef) creation}

If lobster populations are limited, in part, by the availability of refuges for juveniles, then construction of new rocky reefs represents another restoration option. Juvenile and adult American lobsters utilize artificial reefs constructed of concrete or stone, with the spacing and orientation of reefs having a significant effect on occupancy (Scarratt 1968, Sheehy 1976, Castro et al. 2001). Similar studies on Homarus gammarus in Europe, and other lobster species elsewhere, suggest that enhancement of local stocks is possible using appropriately designed reefs, in cases where structured habitat is limiting to the local population (Jensen et al. 1994, Spanier 1994). Structural habitat construction has been used to mitigate dredginginduced losses of Dungeness crab in an estuary in Washington, USA (Wainwright et al. 1992, Dumbauld et al. 1993). However, there is an on-going debate as to whether artificial reefs actually increase fish and invertebrate (or lobster) production, rather than merely attracting individuals already established in nearby natural habitat (Lindberg 1997, Castro et al. 2001, Powers et al. 2003, in this Theme Section).

Castro et al. (2001) monitored abundance, size, and sex of lobsters colonizing 6 experimental artificial reefs in Narragansett Bay, Rhode Island. They found that the density of YOY on artificial reefs matched that on control natural reefs. Although it is possible that the lobsters that settled and survived on the artificial reef would have done so at the same rates elsewhere on natural reefs had the new reef not been installed, the reef does represent new nursery habitat for lobsters. The work of Wahle and co-workers (Wahle \& Steneck 1991, 1992, Wahle \& Incze 1997, Casrto et al. 2001) indicates that postlarvae settle in cobble reef areas. Given the evidence for habitat limitation of EBP lobsters, placement of cobble reef containing mixed sizes of cobble and boulders seems likely to enhance postlarval settlement, and possibly also adult production if larval supply is locally sufficient. Nevertheless, habitat enhancement for lobsters has not been shown experimentally to augment lobster stocks beyond the local reef area, and thus may not be an appropriate restoration strategy.

\section{Reduction in fishing mortality}

Services provided by adult lobsters include supporting a fishery, producing eggs to support the next generation of lobsters, and providing ecological services within the food web. Given the existing high exploitation rate such that the lobster population is considered over-fished (as noted above), a restoration strategy with a high likelihood of success would be one which reduced fishing mortality, through modified management, to a level closer to that which would provide the maximum sustainable yield to the fishery. This would be the population level providing the most ecological production (production entering the food web) as well. Fisheries management is the focus of considerable professional effort (e.g. NMFS 1996). However, uncertainty prevails in the assessment of stock abundances and in determining the fishing rate that provides the maximum sustainable yield (Ludwig et al. 1993), making this approach difficult to implement, particularly in the face of resistance by the fishing industry. Furthermore, limitation of lobster catches would entail a loss of human use, at least in the short term. Consequently, choosing this option would induce another injury to human services, which would require compensation, thereby indirectly adding to the costs of the spill. In the particular case of compensation for injuries caused by the North Cape oil spill, there was a desire not to impact the fishery further. Thus, an alternative that accomplished a reduction in $F$, while not penalizing the fishermen in the local area, was pursued.

\section{Purchase and release of harvested females}

One means of enhancing adult female lobsters without simultaneously diminishing the use of the resource by fishermen would be to purchase lobsters from fishermen and release them back to the wild population. The returned females can be v-notched (i.e. marked with a v-shaped cut in the tail), with a regulatory prohibition against taking or selling any v-notched lobster. This action would provide an immediate boost to adult lobster abundance over that which would otherwise prevail. Subsequently, the fishing mortality would be greatly reduced on those released adult female lob- 
sters, thereby increasing lifetime egg production. If egg production and larval supply limit lobster settlement and ultimately constrain the abundance of adults, then this restoration option would have short- and long-term benefits of enhancing lobster abundance.

The fate of the eggs produced by these restocked adult females is uncertain. The dispersal of lobster larvae by currents during their 20 to $40 \mathrm{~d}$ larval life makes it difficult to predict settlement locations. In addition, it would be difficult to disentangle the effects of the restocking program from other factors that drive interannual variation in local larval abundances and adult lobster populations. Nevertheless, the present lobster management efforts by state and federal agencies target increasing egg production. Therefore, the proposed restocking project is consistent with current lobster management measures. Furthermore, the states of Massachusetts, Rhode Island, Connecticut, and New York have already passed a prohibition on the possession of v-notched female lobsters as part of the implementation of regional lobster management plans. Lobster harvesters holding a permit to fish in Federal waters are also prohibited from possessing v-notched lobsters. Given the lobsters' migratory behavior and the mobility of harvesters, a regionally recognized and enforceable marking system is critical to realizing the full measure of success from this restoration option.

\section{METHODS FOR SCALING RESTORATION ALTERNATIVES}

The use of ecological restorations to compensate for services lost because of injury to natural resources implies a need to scale the restoration to equal the loss. In our application, restoration should account for: (1) the sex ratio of killed lobsters; (2) the size distribution of killed lobsters; (3) the survivorship between life stages; (4) the delay between the kill and implementation of the restoration project; and (4) the time required for growth and maturation of lobsters into the age classes lost. The accounting involves population modeling, using the life table developed earlier. The same units and demographic parameters should be employed for measuring injury and benefits of restoration, such that the scale of the restoration is indeed compensatory. Compensation includes application of economic discounting, so that when restoration has been completed, its value matches the interim loss to the resource. In other words, the lag time is compensated by effectively paying interest, but in terms of additional restoration over-and-above that required to return the resource to the baseline population level had there not been a spill.

\section{Stocking with juveniles raised in hatcheries}

The total kill was equivalent to 7.2 billion postlarval lobsters, of which 4.33 billion were females (Table 5). Since females produce eggs to replenish the stock, if egg production limits the lobster population size, then replacement of lost females with males would not be entirely compensatory. Assuming that the hatchery produces equal numbers of males and females, the appropriate replacement number would need to be 8.66 billion postlarvae (twice the female loss). However, because it would take some number of years both to develop the hatchery program and for the lobsters to grow up to the ages lost, more than 8.7 billion females would be required to compensate for the loss and for the time gap between injury and restoration.

Delays between injury and instigation of restoration can be handled by an additional factor $(1+d)^{\lambda}$, where $\lambda$ is the number of years of lag (after 1996 when the injury occurred) before the restoration begins, and $d$ is the annual discount rate, which is typically set at $3 \%$ $(d=0.03$ : NOAA 1997). In addition, the number of years required for postlarval lobsters to grow into each age class lost (i.e. $t=$ the age of a size class in Table 3 ) needs to be compensated. The compensation number of post larvae $\left(N_{\mathrm{PL}}\right)$ is calculated as

$$
N_{\mathrm{PL}}=\Sigma\left[\mathrm{PL}_{t}(1+d)^{\lambda+t}\right]
$$

where $\mathrm{PL}_{t}$ is the number of postlarval equivalents for age class $t$. Thus, in this case, $\Sigma \mathrm{PL}_{t}=8.7$ billion. Assuming, for example, that the hatchery stocking all occurred in 2001, 5 yr after the spill $(\lambda=5), N_{\mathrm{PL}}=11$ billion (Table 6).

\section{Habitat (rock reef) creation}

Assuming that structural habitat is limiting to EBP lobsters, creation of new cobble reef would increase their numbers produced by the spawning adults present in the population. The scaling of the area of reef needed requires an estimate of the density of new lobsters provided per unit reef area. Quantifying the gain as $1.5 \mathrm{yr}$ old lobsters that are 17 to $27 \mathrm{~mm} \mathrm{CL}$, a cobble reef in Rhode Island might be expected to produce $0.89 \mathrm{EBP} \mathrm{m}^{-2}$ $\mathrm{yr}^{-1}$ (Table 1). This production would be gained every year indefinitely over the lifetime of the reef, but future gains must be discounted $3 \%$ annually. Thus, the total production (TP) over n years of project life is:

$$
\mathrm{TP}=P \sum(1 /(1+d))^{\mathrm{n}}
$$

where $P$ is the annual augmented production (0.89 EBP $\mathrm{m}^{-2} \mathrm{yr}^{-1}$ ). If $\mathrm{n}$ exceeds $100 \mathrm{yr}, T P$ levels off at $31.6 P$. Thus, assuming the reef to be permanent, TP $=28.2$ EBP per $\mathrm{m}^{2}$ of reef. The amount of reef needed for full compensation is computed as: 
Table 6. Homarus americanus. Scale of hatchery stocking required for compensation of lobster loss due to the North Cape oil spill, incorporating economic discounting to account for the time-lag between the year the age class was killed and is replaced. In this example, it is assumed that the hatching of lobsters occurred entirely in the summer of 2001, $5.5 \mathrm{yr}$ after the spill. CL: carapace length

\begin{tabular}{|ccccc|}
\hline CL (mm) & $\begin{array}{c}\text { Required } \\
\text { postlarval } \\
\text { equivalents } \\
\text { (millions) }\end{array}$ & $\begin{array}{c}\text { LAG } \\
\text { (yr) }\end{array}$ & $\begin{array}{c}\text { Discount } \\
\text { factor }\end{array}$ & $\begin{array}{c}\text { Compensation } \\
\text { \# (millions) }\end{array}$ \\
\hline 7 & 0.05 & 5.8 & 1.3 & \\
12 & 111 & 6.0 & 1.3 & 0.06 \\
17 & 787 & 6.3 & 1.4 & 947 \\
22 & 1022 & 6.5 & 1.4 & 1238 \\
27 & 1126 & 6.7 & 1.4 & 1374 \\
32 & 987 & 7.0 & 1.4 & 1212 \\
37 & 881 & 7.2 & 1.4 & 1091 \\
42 & 851 & 7.5 & 1.4 & 1061 \\
47 & 674 & 7.7 & 1.5 & 847 \\
52 & 538 & 8.0 & 1.5 & 681 \\
57 & 438 & 8.3 & 1.5 & 560 \\
62 & 374 & 8.6 & 1.5 & 482 \\
67 & 249 & 8.9 & 1.5 & 323 \\
72 & 223 & 9.2 & 1.6 & 292 \\
77 & 163 & 9.6 & 1.6 & 216 \\
82 & 123 & 9.9 & 1.6 & 165 \\
87 & 48 & 10.3 & 1.7 & 65 \\
92 & 41 & 10.7 & 1.7 & 56 \\
97 & 11 & 11.1 & 1.7 & 15 \\
102 & 5 & 11.5 & 1.8 & 8 \\
107 & 9 & 12.0 & 1.8 & 12 \\
Total & 8661 & & & 10779 \\
& & & & \\
\hline
\end{tabular}

Compensation area $\left(\mathrm{m}^{2}\right)=\left\{\sum\left[\mathrm{EBP}_{t}(1+d)^{\lambda+t}\right]\right\} / \mathrm{TP}$

where $\mathrm{EBP}_{t}$ is the number of EBP equivalents for age class $t$ (scaled as $22 \mathrm{~mm} \mathrm{CL}$ and age $1.5 \mathrm{yr}$, the same size and age class as for TP) and $\lambda$ is the number of years of lag after 1996 when the injury occurred before the reef is created. In this case, $\Sigma \mathrm{EBP}_{t}=17$ million as $22 \mathrm{~mm} \mathrm{CL}$ equivalents, after multiplying 14 million $22 \mathrm{~mm}$ equivalents of both sexes (Table 5) by 1.2 to account for the fact that $60 \%$ of the kill was female, and twice the female number is needed in compensation. Assuming, for example, that the reef was built in $2001,5 \mathrm{yr}$ after the spill $(\lambda=5)$, the compensating amount of reef would be $0.74 \mathrm{~km}^{2}$.

\section{Reduction in fishing mortality}

Scaling the required change in $F$ to compensate for interim losses from a spill could be accomplished in several ways. One method would be to calculate the production foregone because of the spill (i.e. the lost biomass production in the dead individuals plus the growth they would be expected to have undergone before death) and balance that with production gained by the change in fishing mortality rate. The methodology for these calculations is beyond the scope of the present analysis. Several production foregone models are available that could be used in scaling (e.g. Ricker 1975, Rago 1984, Jensen et al. 1988, Polacheck et al. 1993, Prager 1994).

An alternative approach is to use egg production as currency. Table 4 provides an estimate of lifetime egg production per $7 \mathrm{~mm}$ female in the population, assuming equilibrium and a self-sustaining inshore population. If the value of $F$ is changed (for all females recruited to the fishable population), lifetime egg production per $7 \mathrm{~mm}$ female changes. The net gain in egg production per female times the number of $7 \mathrm{~mm}$ females in the stock represents the net gain of the restoration program. For example, in NMFS Area 539, there were approximately 1.4 million lobsters of fishable size in the late 1990s (Gibson et al. 1997b). Assuming that $50 \%$ of these are female $(0.7$ million legal females), and by summing $L X$ for $>82.6 \mathrm{~mm}$ females from Table 4 , to obtain $444 \times 7 \mathrm{~mm}$ females per legal female in the stock, there were 311 million $7 \mathrm{~mm}$ females in Area 539. If the value of $F$ in Area 539 changed from 0.97 to 0.755 for $10 \mathrm{yr}$, by recalculation of Table 4 (not shown) the net gain in $7 \mathrm{~mm}$ lobsters produced would just equal the number of $7 \mathrm{~mm}$ lobsters required for compensation (907 million, which is equal to twice the female equivalents lost, i.e. 729 million, times the discounting factors for each age class, as in Table 6, accounting for delay in realization of the gains). Thus, a modest reduction in $F$ could increase the numbers of larger females in the population, providing a sufficient net gain in reproduction to offset losses from the spill. However, it should be noted that this calculation assumes a high survival rate from egg to $7 \mathrm{~mm}$ of $6.6 \%$. If the survival rate from egg to $7 \mathrm{~mm}$ is actually $1 \%$ (or $0.3 \%$ ), as indicated by the empirical analysis, the required $F$ for a 10 yr program would be 0.47 (or 0.14). There are many possible scenarios involving changes in fishing mortality rate that could be scaled (and all are sensitive to the choice of egg-to-7mm survival rate). In the following section, the restoration plan used for the North Cape spill (NOAA et al. 1999) will illustrate scaling for a specific change in $F$.

\section{Purchase and release of harvested females}

In a v-notching program, females returned to the sea have a lower fishing mortality than un-notched females. Scaling to calculate the required number of $\mathrm{v}$-notched females involves use of the life table method 
in Table 4, with egg production as the metric. The lifetime egg production of a female from the size when it was v-notched is calculated with an altered value of $F$ applied for the number of molt cycles where there is protection from harvest. Subsequent to that time, the value of $F$ returns to that of the normal (un-notched) population. Thus, to estimate the numbers of lobsters required for a lobster-restocking program, one uses the total number of eggs demographically equivalent to the numbers killed summed over all age classes (Table 5). Because $60 \%$ of the killed lobsters were females, the compensating number of egg equivalents is twice the female loss: 11 billion eggs. (For clarity, only the results assuming the equilibrium-implied $6.6 \%$ survival from egg to $7 \mathrm{~mm}$ are followed through here. A much larger project would be required if eggto- $7 \mathrm{~mm}$ survival rate is in fact $1 \%$ or lower.) The killed lobsters will be replaced (eventually) once that equivalent number of eggs is re-supplied through augmenting survival and egg production of notched females.

Economic discounting must still be applied to account for the delay between dates of loss and restoration. The total value for restoration gains over all years (TV), expressed as value in the year of the spill, is as follows, where $V_{\mathrm{n}}$ is value $\mathrm{n}$ years after the spill:

$$
\mathrm{TV}=\sum V_{\mathrm{n}}[1 /(1+d)]^{\mathrm{n}}
$$

In this case, the value gained after $n$ years results from future egg production and maturation to the size classes lost during the spill. The lag time for the gain, $\mathrm{n}$, is the sum of the number of years before females are v-notched and restocked, the lag before eggs are produced, and the years required for eggs to mature into animals of each age killed. Example calculations are provided below.

\section{SELECTED ALTERNATIVE FOR NORTH CAPE RESTORATION PLAN}

Each of the 4 restoration alternatives was considered for restoring lobsters injured by the North Cape oil spill before one was selected. The number (11 billion) of post-larvae needed from a lobster hatchery to compensate for the loss was considered by the federal and state trustees as too great to be logistically feasible or economically reasonable. Furthermore, if all these lobsters were to be added simultaneously, or even spread out over a few years, there is real potential for density-dependent mortality through predation or interference competition for refuges. The ecological consequences of such a substantial pulse of small lobsters may not be desirable and may induce negative impacts that are difficult to anticipate. This problem is in fact unavoidable, as the spill induced a perturbation to the population which will take time to recover via new settlement or a restoration project. There may be an over-shoot and density dependent compensation in the recovery curve, which could be magnified (or damped) by restoration. Our present knowledge of density-dependent adjustment of population parameters is rudimentary, at best, for most, if not all, fishery species.

The cobble reef area required to compensate for the lobster losses from the North Cape oil spill is $0.74 \mathrm{~km}^{2}$. When this option was considered by the trustees, given the assumption that habitat creation would in fact result in a net gain to the population, the main concern was where to locate a reef that large. The reef should presumably be placed in Block Island Sound near the spill impact zone so the compensation would occur in the area of impact. However, the reef would necessarily displace existing soft-bottom habitat (inducing another ecological loss that would need to be compensated) and disrupt fish trawling in the area, constituting a reduction in fishing grounds for the demersal fishery. Because fishermen had already suffered a large loss due to the spill, and given the uncertainty that habitat is limiting the local population, this option was not pursued.

The reduction of fishing effort and rates on either both sexes or on females (which would provide additional life-time egg production) would effectively restore the population, but would also represent a short-term loss to fishermen, who were not responsible for the impact caused by the spill. Given the large private losses to fishermen during the period after the North Cape oil spill, and the high uncertainty associated with estimating the appropriate compensation to the individual fishermen for additional losses imposed by such a prohibition, this option was not implemented. However, in a situation where restoration is not in compensation for injury caused by a private party (as in this oil spill) or where the fishermen's losses can be appropriately compensated, and particularly where a population is severely over-fished, the most effective restoration method would be reduction in fishing rate.

Restocking by release of adult female lobsters purchased from the fishery was the restoration option chosen for compensation in the North Cape case. This option effectively reduces fishing mortality $(F)$, but does not impose added restrictions on the fisherman's catch and profits. A 5 yr program of purchase, v-notching, and release was designed to minimize ecological perturbations and skewing of the sex ratio, as well as to avoid influencing market prices for lobsters. In addition, an extended time frame rendered the logistics of this restocking more feasible and less of a perturbation to the local lobster population. 


\section{SCALE OF RESTORATION REQUIRED TO COMPENSATE FOR THE LOSS}

The scaling calculations began with the development of size-specific survival rates (Table 3). We then converted the loss of lobsters across multiple size (age) classes into the numbers of eggs that had produced those animals lost, assuming this mortality schedule. Initial life-table assumptions differed from those presented here, resulting in an estimate that the spill mortality represented a loss of 18 billion eggs (Gibson 1998, French 1999). Based on new data compiled in ASMFC (2000), the killed lobsters derived from 9.2 billion eggs, 5.5 billion of which were female (Table 5). Assuming the same mortality schedule after restoration (Table 3), replacement of 11 billion eggs would be expected eventually to replace all lost females and thus their progeny, restoring both sexes in subsequent generations.

Our next step was to estimate the quantitative augmentation of egg production expected from the restocking program, and to calculate how many females were required to replace the numbers of eggs equivalent to the lobster kill. We assumed the following: (1) Female lobsters of legally fished sizes will be purchased from the fishery, v-notched, returned to the area where they were caught, and will receive regulatory protection from future harvest; (2) Handling losses will be $5 \%$; (3) The fishing mortality on v-notched lobsters would be $50 \%$ of the normal rate; (4) The v-notch would last 1 to 2 molts, with $50 \%$ protection from fishing through the first molt and $25 \%$ after a second molt; and (5) Lobster demographic parameters will not change after restocking.

Using these assumptions, we computed a new life table for $90 \mathrm{~mm}$ CL v-notched lobsters (Table 7). For the sake of clarity, and as a first step, the Table 7 calculations include discounting for the lag time in production of eggs after the date of restocking females, but not for the time lag between the kill and initiation of the $5 \mathrm{yr}$ restocking program followed by development to the size classes lost. The resulting calculations indicate that each $90 \mathrm{~mm}$ female would be expected to produce 4260 eggs in her lifetime. Accounting for the time delays before the eggs are produced after v-notching, the egg production has a discounted value of 4083 eggs per female.

Complete discounting to compensate for the interim loss of lobsters and their services must include the following time lags: (1) the time between the kill, 1996, and the date of restocking of $90 \mathrm{~mm}$ females, from 2000 to 2004 (4 to $8 \mathrm{yr}$ ); (2) the time between restocking a $90 \mathrm{~mm}$ female and the production of eggs ( $1 \mathrm{yr}$ plus discounting in Table 7); (3) the time required for eggs to develop to the ages of those lobsters killed (1 to $4 \mathrm{yr}$ ); and (4) correction for the fact that the v-notched females immediately replace the lost legal lobsters ( $\geq 5 \mathrm{yr}$ old). For example, 15 to $35 \mathrm{~mm}$ lobsters are ca. $2 \mathrm{yr}$ old. This age class of lobsters killed would have reached legally fishable size in 2000 . They were eggs in 1994. Restocking of females in 2000 would produce eggs in 2001. Consequently, there is a $7 \mathrm{yr}$ lag in the replacement of juvenile lobsters that were ca. 2 yr old in January 1996. Similarly, there is an 8 yr time lag for the 2 yr-olds killed, and so on.

The computations that discount for all these time lags are relatively straightforward. The demographically equivalent number of eggs for each age class to be produced by restocked females is discounted annually over the number of years of lag, from the year the killed lobsters were eggs to the year eggs replacing them will appear. Using a $3 \%$ annual discount rate $(d)$,

Table 7. Homarus americanus. Eggs produced per v-notched $90 \mathrm{~mm}$ CL female, assuming that restocking occurred in 1996. Molts: number of molts after 90-mm stage; CL: carapace length in mm; $I_{\mathrm{d}}$ : intermolt duration (yr); Age is calculated from length using relationship from Gibson (1998); F: instantaneous fishing mortality rate; Survival (to next molt) is calculated as $\mathrm{e}^{-(F+M) \Delta t}$ where $M$ is instantaneous natural mortality rate, 0.1 , and $\Delta t$ is years from that size class to the next; $P_{\text {mat }}$ : fraction ovigorous; $f$ : fecundity (eggs per clutch); $M_{X}$ : eggs per female at age $X$. Number (\#) of eggs for each CL class is calculated as the fraction of v-notched females surviving to that class multiplied by $M_{X}$. Discounting at $3 \% \mathrm{yr}^{-1}$ for the number of years after 1996 when eggs would be produced is applied, to calculate discounted numbers of eggs by class, assuming females are v-notched in 1996

\begin{tabular}{|c|c|c|c|c|c|c|c|c|c|c|c|}
\hline Molts & $\begin{array}{c}\mathrm{CL} \\
(\mathrm{mm})\end{array}$ & $I_{\mathrm{d}}$ & $\begin{array}{c}\text { Age } \\
(\mathrm{yr})\end{array}$ & $\begin{array}{l}\text { Fraction } \\
\text { protected }\end{array}$ & $F$ realized & Survival & $P_{\text {mat }}$ & $f$ & $M_{X}$ & \# eggs & $\begin{array}{c}\text { \# eggs } \\
\text { discounted }\end{array}$ \\
\hline 0 & 90 & 2.0 & 5.5 & 0.500 & 0.49 & 0.310 & 0.986 & 11398 & 11240 & 3314 & 3217 \\
\hline 1 & 100 & 2.9 & 7.5 & 0.500 & 0.49 & 0.188 & 0.999 & 17000 & 16981 & 939 & 859 \\
\hline 2 & 111 & 6.9 & 10.4 & 0.250 & 0.73 & 0.00334 & 1.000 & 25189 & 36198 & 7 & 6 \\
\hline 3 & 124 & 7.0 & 17.3 & 0.00 & 0.97 & 0.00056 & 1.000 & 37106 & 54200 & 0.006 & 0.004 \\
\hline 4 & 137 & 7.0 & 24.3 & 0.00 & 0.97 & 0.00056 & 1.000 & 54377 & 79427 & 0.000 & 0.000 \\
\hline 5 & 152 & 7.0 & 31.3 & 0.00 & 0.97 & 0.00056 & 1.000 & 79320 & 115859 & 0.000 & 0.000 \\
\hline 6 & 168 & 7.0 & 38.3 & 0.00 & 0.97 & 0.00056 & 1.000 & 115225 & 168305 & 0.000 & 0.000 \\
\hline Total & & & & & & & & & & 4260 & 4083 \\
\hline
\end{tabular}


the number of females required to replace that age class $L$ years after the spill $\left(N_{A, L}\right)$ is calculated as:

$$
N_{A, L}=N_{A}\left[(1+d)^{L}\right]
$$

where $N_{A}=$ is the number of adult females needed to produce the necessary egg equivalents for Age Class A. Table 8 presents calculations of adjustment factors (the discounting term in the equation), assuming that all restocking were to occur in 2000 or from 2000 to 2004 in equal numbers over the 5 yr period. Computationally, the required adjustments for discounting can be simplified by applying a single factor derived from integrating over all age classes, 1.26 for restocking in 2000 and 1.33 for restocking from 2000 to 2004 (Table 8). Thus, if all v-notching occurred in 2000, the number of $90 \mathrm{~mm}$ CL females required would be 3.4 million [= 1.26(11 billion eggs/4083 eggs per female)]. Assuming a $5 \mathrm{yr}$ restoration program, the compensation number is 3.6 million v-notched $90 \mathrm{~mm}$ CL females $[=1.33(11$ billion eggs $/ 4083$ eggs per female)]. Again, these results are assuming egg-to$7 \mathrm{~mm}$ survival is $6.6 \%$. If this survival is only $1 \%$, 23 million females would be required in a 5 yr program.

The compensation number is very sensitive to assumptions made in the scaling calculations within the range of uncertainty. Most of the uncertainty is related to the survival schedule assumed for lobsters less than legal size, particularly for the egg-to- $7 \mathrm{~mm}$

Table 8 . Homarus americanus. Computation of effects of discounting by $3 \% \mathrm{yr}^{-1}$ for time lags between lobster loss and restoration. Discounting accounts for time lag between the kill, initiation of restocking, the time after restocking before females begin to produce eggs (1 yr), and development to each size class of lobster lost (if $<5 \mathrm{yr}$ ). Legal lobsters $\geq 5 \mathrm{yr}$ are replaced immediately at the time of v-notching. Lags are weighed by the proportion of egg-equivalents killed in each age class, and summed for all age classes to develop correction factors

(1/summed discounted value) to account for the lag before replacement

\begin{tabular}{|lccccc|}
\hline $\begin{array}{l}\text { Age when } \\
\text { killed (yr) }\end{array}$ & $\begin{array}{c}\text { Fraction of } \\
\text { egg } \\
\text { equivalents }\end{array}$ & $\begin{array}{c}\text { Year } \\
\text { were } \\
\text { eggs }\end{array}$ & $\begin{array}{c}\text { Years of } \\
\text { lag } \begin{array}{c}\text { to replace } \\
\text { if all } \\
\text { v-notched } \\
\text { in 2000 }\end{array}\end{array}$ & $\begin{array}{c}\text { Discounted } \\
\text { value } \\
\text { if all } \\
\text { v-notched } \\
\text { in 2000 }\end{array}$ & $\begin{array}{c}\text { Discounted } \\
\text { value for } \\
5 \text { yr } \\
\text { v-notching } \\
\text { program }\end{array}$ \\
\hline 0.5 & 0.0129 & 1995 & 6 & 0.0108 & 0.0102 \\
1.5 & 0.4528 & 1994 & 7 & 0.3682 & 0.3474 \\
2.5 & 0.2779 & 1993 & 8 & 0.2194 & 0.2069 \\
3.5 & 0.1559 & 1992 & 9 & 0.1195 & 0.1127 \\
4.5 & 0.0732 & 1991 & 10 & 0.0545 & 0.0514 \\
5.5 & 0.0197 & 1990 & 4 & 0.0175 & 0.0165 \\
6.5 & 0.0048 & 1989 & 4 & 0.0042 & 0.0040 \\
7.5 & 0.0012 & 1988 & 4 & 0.0011 & 0.0010 \\
8.5 & 0.0006 & 1987 & 4 & 0.0006 & 0.0005 \\
9.5 & 0.0010 & 1986 & 4 & 0.0009 & 0.0008 \\
Total & 1.0000 & & & 0.797 & 0.752 \\
Factor to account for lag before replacement & 1.255 & 1.331 \\
\hline
\end{tabular}

survival rate (which undoubtedly varies by environmental conditions, both spatially and annually). Given a survival schedule, the results are most sensitive to the level of fishing protection assumed for v-notched females. For example, assuming the equilibriuminferred $6.6 \%$ survival for egg to $7 \mathrm{~mm}$, if the $50 \%$ protection assumption were changed to $88 \%$, the compensation number for the $5 \mathrm{yr}$ program would be about one quarter as high, and equivalent to that of the restoration plan actually undertaken (1.2 million females -notched over 5 yr, NOAA et al. 1999). In order of senvity, the remaining assumptions of most importance re the maturation schedule relative to the size of the and intermales, the size of the v-notched females, indirectly to how well the introduced lobsters are protected from fishing mortality. The very high fishing mortality of unprotected females limits the egg production to the first 2 molt cycles, while more protection increases egg production. To illustrate how geographic origin affects maturation schedule, only $42 \%$ of $90 \mathrm{~mm}$ obsters from the Gulf of Maine, USA, are mature and able to produce eggs in the first and most important olt cycle, whereas $99 \%$ of Rhode Island females are mature. Similarly, stocking smaller lobsters, even from Rhode Island waters, reduces realized egg protection because a smaller fraction is ovigorous during the protected molt cycles. For example, the compensation number of $83 \mathrm{~mm}$ CL females taken from Rhode Island would be 4.3 million (for a 5 yr program), as compared to 3.6 million $90 \mathrm{~mm}$ CL lobsters. The intermolt duration influences egg production because it determines how many clutches can be produced before the stocked female is taken by the fishery. This demographic parameter is not well characterized, providing uncertainty in our computations.

The compensation number of 3.4 million $90 \mathrm{~mm}$ CL females (as well as the 1.2 million females to be $\mathrm{v}$-notched in the implemented restoration plan, NOAA et al. 1999) is greater than the total number of legal females in NMFS Area 539 at any given time ( 0.7 million; Gibson et al. 1997b). Thus, the v-notching has to be implemented over a number of years (e.g. the implemented plan was to v-notch 246000 for each of 5 yr). The revised compensation number of 3.4 million estimated here, applied to a 5 yr plan, infers that no female lobsters could be taken in the harvest $(F=1$, so annual catch of females is equal to 
standing stock, 0.7 million, a value equivalent to $1 / 5$ the compensation number). In reality, a restoration project of this size would need to occur over a longer time period than $5 \mathrm{yr}$, to allow for handling losses and less than $100 \%$ protection by the v-notch. Moreover, given such a large compensation requirement, the most effective restoration approach would be to reduce fishing effort directly, as opposed to v-notching, and so reduce the handling and non-compliance losses. This would require appropriate compensation to the fishing industry, related to their lost catch, livelihood and profits due to the initial spill-caused injury and the restoration-induced changes.

A harvest that is highly biased towards males suggests that the sex ratio might be affected enough that mating and sperm availability for fertilization of eggs would become a limitation. The expected change in the sex ratio was evaluated under 2 assumptions: (1) that the v-notched females would mix over the entirety of Area 539, and (2) the v-notched females would be returned to Rhode Island waters, ca. $25 \%$ of Area 539. Under the plan that was actually implemented, the sex ratio would be expected to change over $5 \mathrm{yr}$ from $50 \%$ female to $56 \%$ under Assumption (1), or to $67 \%$ under Assumption (2). Assuming no harvest of females for $5 \mathrm{yr}$, the sex ratio would change to $63 \%$ under Assumption (1) or to $80 \%$ under Assumption (2). If the initial sex ratio is $>50 \%$, the sex ratios would become more skewed. In addition, the females would be larger than the males, which may cause some difficulties in mating (Cobb 1995). In the implemented plan, the return of v-notched females was wide-spread to minimize focusing of returns and skewing of the sex ratio. For larger projects, these calculations indicate that a much longer time frame than 5 yr would be needed, and the compensation number would need to be increased $3 \%$ annually for each year of delay before benefits are accrued.

\section{DISCUSSION}

Our treatment of how restoration of lobsters following a Rhode Island oil spill can be quantitatively matched to compensate for the discounted loss demonstrates a process that can render restoration ecology a more quantitative science. The process of developing an effective restoration plan, and scaling it to fit the quantitative goal, has several components. A review of the life history and ecology of the target species is critical to identify factors likely to be limiting to the injured population. Restoration interventions are effective if they can relieve the influence of one or more limiting factors. Demographic models need to be developed for calculating the scale of restoration needed and for developing a common currency to compare injury and benefits of restoration. The results are very sensitive to the life-history parameters assumed; thus, these need to be quantified carefully to represent the injured population. The concept of discounting so as to compensate for the interim loss of the resource, its ecosystem and human services, represents an important consideration in scaling any restoration project. Lag times inevitably exist between loss and full restoration. These lags include the time between the loss and the initiation of restoration actions, and the time for the project to reproduce the life stages lost.

Many assumptions about the effectiveness of restoration have great uncertainty associated with them. For example, in the absence of previous data, we were forced to estimate handling losses and the effectiveness of regulations prohibiting take of v-notched lobsters. In addition, survival rates of larval and juvenile lobsters are highly uncertain. Restoration ecology possesses a number of tools with which to deal with uncertainty. For example, at the cost of greater effort in restoration planning, a formal uncertainty analysis could be conducted as part of contrasting alternativerestoration options. Such uncertainty information played a role in the rejection of some options by the North Cape trustees, but this was not based on quantitative uncertainty analyses. In environmental management, uncertainty is often handled by enhancing the scale of restorations to better protect public trust resources. Wetland, marsh, and seagrass restorations are commonly conducted over larger areas than the areas removed so as to include uncertainty in the performance of the projects. The replacement ratios used typically increase with the level of uncertainty. Probably the most certain way of handling doubts about the effectiveness of restoration would be to require monitoring of the projects and subsequent adjustments if restoration targets were not met. The quantitative scaling computations that we develop here are best treated as hypotheses and predictions to be tested directly through monitoring of this sort. In the present case of the North Cape, monitoring is being performed and v-notch incidence among females has increased, but complications, such as a dramatic decrease in the stock size since 2000, increasing incidence of shell disease, and delays in the v-notching program, preclude analysis of the success of the restoration program at this time.

The lobster restoration plan that we present here provides a model for a species that is long-lived and which is exploited. The importance of the lobster fishery has led to enough research on the population processes of lobsters to be able to develop a reasonable demographic model to guide restoration scaling for the southern New England stock. For most marine species 
that do not form the basis of a fishery, that information will be inadequate to construct a predictive quantitative demographic model. Furthermore, the intensity of fishing pressure in the lobster fishery and in other fisheries (Pauly et al. 1998) provides several viable and highly effective opportunities for restoration actions not available for species that are not fished. Consequently, the analysis that we present of options to restore lobsters has generic applicability to a large group of marine fish and shellfish that often will represent the most valuable resources, deserving of special attention in restoration. To some degree, special focus on restoring exploited species may stress value to human uses more than value to the ecosystem. However, the decline in fisheries is itself perhaps the greatest conservation challenge in the sea (Botsford et al. 1997, Jackson et al. 2001), so the 2 needs tend to coincide. However, concerns about the broader ecological impacts of enhancing one target species in the system are justified and deserve attention in considering restoration choices. The capability of ecology to make correct predictions is more limited at the level of the community and ecosystem than at the level of individual species populations. Consequently, effectiveness of restoration and conceptual development in ecology can both benefit from developing a full suite of predictions and testing them through monitoring of well-designed restoration projects.

Acknowledgements. This work was supported by NOAA, Damage Assessment Center (DAC), Silver Spring, MD. The biological considerations and scaling calculations were developed after discussions with, and obtaining considerable input from, Saul Saila of the University of Rhode Island, Mike Fogarty of NMFS, Michael Clancy of the University of Rhode Island (now of Boston University), John Catena of NMFS Restoration Center, Carol-Ann Manen of NOAA-DAC, and Steve Moran of RIDEM. Charles (Pete) Peterson of the University of North Carolina at Chapel Hill provided critical guidance, editing, and review of the manuscript, as did 3 anonymous reviewers who provided insightful comments that improved our analysis. We thank Mike Donlan of Industrial Economics for advice and encouragement.

\section{LITERATURE CITED}

Able K, Heck KL, Fahay MP, Roman CT (1988) Use of saltmarsh peat reefs by small juvenile lobsters on Cape Cod, Massachusetts. Estuaries 11:83-86

Addison AT, Bannister RCA (1994) Re-stocking and enhancement of clawed lobster stocks: a review. Crustaceana 67: 131-155

Angell TE (1995) Rhode Island lobster research and management project. 1994 Annual/Completion Report (NOAA Grant No. NA46FI0084. Project No. 3-IJ-77), Rhode Island Division of Fish and Wildlife, Wickford

Angell TE, Lazar NB (1994) Rhode Island lobster research and management project. 1991-1993 Annual/Completion Report (NOAA Grant No. NA36FI0117-01. Project No.
3-IJ-43-3), Rhode Island Division of Fish and Wildlife, Wickford, RI

Anthony VC (1980) A review of lobster mortality estimates in the United States. In: Anthony VC, Caddy JF (eds) Proc Canada-US Workshop Status of Assessment Science for NW Atlantic lobster (Homarus americanus) Stocks. Can Tech Rep Fish Aquat Sci 932:17-26

ASMFC (Atlantic States Marine Fisheries Commission) (2000) American lobster stock assessment report for peer review. Stock Assessment Report No. 00-01 (Supplement), ASMFC, Washington, DC

Bannister RCA, Addison JT (1986) Effect of assumptions about the stock-recruitment relationship on a lobster (Homarus americanus) stock assessment. Can J Fish Aquat Sci 43:2353-2359

Bannister RCA, Addison JT (1998) Enhancing lobster stocks: a review of recent European methods, results, and future prospects. Bull Mar Sci 62:369-387

Bannister RCA, Addison JT, Lovewell SRJ (1994) Growth movement, recapture rate and survival of hatchery-reared lobsters (Homarus gammarus Linnaeus, 1758) released into the wild on the English east coast. Crustaceana 67:156-182

Beck MW (1995) Size-specific shelter limitation in stone crabs: a test of the demographic bottleneck hypothesis. Ecology 7:968-980

Beck MW (1997) A test for the generality of the effects of shelter bottlenecks in four stone crab populations. Ecology 78: $2487-2503$

Bibb BG, Hersey R (1979) Distribution and abundance of lobster larvae in Block Island Sound, 1978. Final Report to New England Power, Raytheon Environmental Services, Portsmouth, RI

Botsford LW, Catilla JC, Peterson CH (1997) The management of fisheries and marine ecosystems. Science 277:509-515

Caddy JF (1986) Modeling stock-recruitment processes in Crustacea: some practical and theoretical perspectives. Can J Fish Aquat Sci 43:2330-2344

Castro KM, Cobb JS, Wahle RA, Catena J (2001) Habitat addition and stock enhancement for American lobsters, Homarus americanus. Mar Freshw Res 52:1253-1261

Clark JA, Hoekstra JM, Boersma PD, Kareiva P (2002) Improving US Endangered Species Act recovery plans: key findings and recommendations of the SCB recovery plan project. Conserv Biol 16:1510-1519

Cobb JS (1971) The shelter-related behavior of the lobster, Homarus americanus. Ecology 52:108-115

Cobb JS (1995) Interface of ecology, behavior, and fisheries. In: Factor JR (ed) Biology of the lobster Homarus americanus. Academic Press, New York, p 139-151

Cobb JS, Booth JD, Clancy M (1997) Recruitment strategies in lobsters and crabs: a comparison. Mar Freshw Res 48: 797-806

Cobb JS, Clancy M, Wahle RA (1999) Habitat-based assessment of lobster abundance: a case study of an oil spill. Am Fish Soc Symp 22:285-298

Dickie LM, Kerr SR, Boudreau PR (1987) Size-dependent processes underlying regularities in ecosystem structure. Ecol Monogr 57:233-250

Dumbauld BR, Armstrong DA, McDonald TL (1993) Use of oyster shell to enhance intertidal habitat and mitigate loss of Dungeness crab (Cancer magister) caused by dredging. Can J Fish Aquat Sci 50:381-390

Ennis GP (1980) Recent and current Canadian research on growth of lobsters in the wild. In: Anthony VC, Caddy JF (eds) Proc Canada-US Workshop Status of Assessment Science for NW Atlantic lobster (Homarus americanus) Stocks. Can Tech Rep Fish Aquat Sci 932:9-15 
Ennis GP (1995) Larval and postlarval ecology. In: Factor JR (ed) Biology of the lobster Homarus americanus. Academic Press, New York, p 23-46

Fogarty MJ (1995) Populations, fisheries, and management. In: Factor JR (ed) Biology of the lobster Homarus americanus. Academic Press, New York, p 111-137

Fogarty MJ (1998) Implications of migration and larval interchange in American lobster (Homarus americanus) stocks: spatial structure and resilience. Proc North Pacific Symp Invertebrate Stock Assessment and Management. Can Spec Pub Fish Aquat Sci 125:273-283

Fogarty MJ, Idoine JS (1986) Recruitment dynamics in an American lobster (Homarus americanus) population. Can J Fish Aquat Sci 43:2368-2376

Fogarty MJ, Idoine JS (1988) Application of a yield and egg production model based on size to an offshore American lobster population. Trans Am Fish Soc 117:350-362

French DP (1999) North Cape oil spill: synthesis of injury quantification and restoration scaling for lobsters. Report to NOAA Damage Assessment Center, Silver Spring, MD (part of case administrative record, available at www. darp.noaa.gov/neregion/ncape.htm)

French McCay DP (2003) Development and application of damage assessment modeling: Example assessment for the North Cape oil spill. Mar Pollut Bull 47:341-359

Gibson MR (1998) Potential egg production from lobsters killed in the North Cape oil spill and replacement estimates using recycled commercial catch. Division of Fish and Wildlife, Rhode Island Dept of Environmental Management, Wickford (part of case administrative record, available at www.darp.noaa.gov/neregion/ncape.htm)

Gibson MR, Angell TE, Lazar NB (1997a) Estimation of lobster strandings following the North Cape oil spill in Block Island Sound. Research Reference Document 97/1, Division of Fish and Wildlife, Rhode Island Dept of Environmental Management, Wickford (part of case administrative record, available at www.darp.noaa.gov/neregion/ ncape.htm)

Gibson MR, Angell TE, Lazar NB (1997b) Equivalent adult estimates and stock status of lobster involved in the North Cape oil spill in Block Island Sound. Research Reference Document 97/2, Division of Fish and Wildlife, Rhode Island Dept of Environmental Management, Wickford (part of case administrative record, available at www. darp.noaa.gov/neregion/ncape.htm)

Goodyear CP (1977) Mathematical methods to evaluate entrainment of aquatic organisms by power plants. Report FWS/OBS-76/20.3, US Fish Wildl Serv, Washington, DC

Harding GC, Vass WP, Drinkwater KF (1982) Aspects of larval American lobster (Homarus americanus) ecology in St. Georges Bay, Nova Scotia. Can J Fish Aquat Sci 39: $1117-1129$

Herrick FH (1909) Natural history of the American lobster. Bull US Fish Comm 29:147-408

Hoenig J (1983) Empirical use of longevity data to estimate mortality rates. Fish Bull 82:898-903

Hoenig J, Choudary Hanumara R (1982) A statistical study of seasonal growth models for fishes. Tech Rep Dept Comp Sci Stat, University of Rhode Island, Kingston

Horst TJ (1975) The assessment of impact due to entrainment of ichthyoplankton. In: Saila SB (ed) Fisheries and energy production: a symposium. Lexington Books, Lexington, MA, p 107-118

Hudon C (1987) Ecology and growth of postlarval and juvenile lobster, Homarus americanus, off Îles de la Madeleine (Quebec). Can J Fish Aquat Sci 43:2243-2247

Hudon C, Lamarche G (1989) Niche segregation between
American lobster Homarus americanus and rock crab Cancer irroratus. Mar Ecol Prog Ser 52:155-168

Hudon C, Fradette P, Legendre P (1986) La répartition horizontale et verticale des larvae de homard (Homarus americanus) autour des Iles de la Madeleine, Golfe du SaintLaurent. Can J Fish Aquat Sci 43:2164-2176

Incze LS, Wahle RA, Cobb JS (1997) Quantitative relationships between postlarval production and benthic recruitment in lobsters, Homarus americanus. Mar Freshw Res 48:729-743

Incze LS, Wahle RA, Palma AT (2000) Advection and settlement rates in a benthic invertebrate: recruitment to first benthic stage in Homarus americanus. ICES J Mar Sci 57: $430-437$

Jackson JBC, Kirby MX, Berge WH, Bjorndal KA and 15 others (2001) Historical overfishing and the recent collapse of coastal ecosystems. Science 293:629-638

James-Pirri MJ (1996) The influence of settlement time on post-settlement growth in the American lobster (Homarus americanus). PhD thesis, University of Rhode Island, Kingston

Jensen AC, Collins KJ, Free EK, Bannister RC (1994) Lobster (Homarus gammarus) movement on an artificial reef: the potential use of artificial reefs for stock enhancement. Crustaceana 67:198-211

Jensen AL, Reider RH, Kovalak WP (1988) Estimation of production foregone. North Am J Fish Manage 8:191-198

Katz CH, Cobb JS, Spaulding M (1994) Larval behavior, hydrodynamic transport, and potential offshore-to-inshore recruitment in the American lobster Homarus americanus. Mar Ecol Prog Ser 103:265-273

Lawton P, Lavalli KL (1995) Postlarval, juvenile, adolescent, and adult ecology. In: Factor JR (ed) Biology of the lobster Homarus americanus. Academic Press, New York, p 47-88

Lindberg WJ (1997) Can science resolve the attractionproduction issue? Fisheries 22:10-13

Lipcius RN, Stockhausen WT, Eggleston DB, Marshall LS Jr, Hickey B (1997) Hydrodynamic decoupling of recruitment, habitat quality and adult abundance in the Caribbean spiny lobster: source-sink dynamics? Mar Freshw Res 48:807-815

Ludwig D, Hilborn R, Walters C (1993) Uncertainty, resource exploitation, and conservation: lessons from history. Science 260:17-18

MacKenzie C, Moring JR (1985) Species profiles: life histories and environmental requirements of coastal fishes and invertebrates (North Atlantic) - American lobster. US Fish Wildl Serv Biol. Rep 82(11.33), US Army Corps of Engineers, TR EL-82-4

Mauchline J (1977) Growth of shrimps, crabs, and lobstersan assessment. J Cons Int Explor Mer 37:162-169

Mauviot CJ, Castell JD (1976) Molt-and growth-enhancing effects of bilateral eyestalk ablation on juvenile and adult American lobsters (Homarus americanus). J Fish Res Board Can 33:1922-1229

Miller RJ, Mann KH, Scarratt DJ (1971) Production potential of a seaweed-lobster community in eastern Canada. J Fish Res Board Can 28:1733-1738

Miller RJ, Campbell A, Sharp GJ, Hudon C (1992) Are small juvenile lobsters habitat limited? Can Tech Rep Fish Aquat Sci 1390:55-61

NMFS (National Marine Fisheries Service) (1996) Stock assessment review committee (SARC) consensus summary of assessments. 22nd Northeast Regional Stock Assessment Workshop, NEFSC Ref Doc 96-13. NMFS, Woods Hole

NOAA (National Oceanic and Atmospheric Administration) (1997) Natural resource damage assessment guidance 
document: scaling compensatory restoration actions (Oil Pollution Act of 1990). NOAA Damage Assessment Center, Silver Spring

NOAA (National Oceanic and Atmospheric Administration), Rhode Island Department of Environmental Management (RIDEM), US Department of the Interior (USDOI), and US Fish and Wildlife Service (USFWS) (1999) Restoration plan and environmental assessment for the January 19, 1996 North Cape oil spill, revised draft for public comment, March 31, 1999. NOAA, Silver Spring, MD

Olla BL, Davis MW, Ryer CH (1998) Understanding how the hatchery environment represses or promotes the development of behavioral survival skills. Bull Mar Sci 62:531-550

Pauly D, Soriano-Bartz M, Moreau J, Jarre-Teichmann A (1992) A new model accounting for seasonal cessation of growth in fishes. Aust J Mar Freshw Res 43:1151-1156

Pauly D, Christensen V, Dalsgaard J, Froese R, Torres F Jr (1998) Fishing down marine food webs. Science 279: 860-863

Pennington M (1983) Efficient estimators of abundance for fish plankton surveys. Biometrics 39:281-286

Perkins HC (1971) Egg loss during incubation from offshore northern lobsters (Decapoda: Homaridae). Fish Bull 69: 451-453

Peters RH (1983) The ecological implications of body size. Cambridge studies in ecology. Cambridge University Press, Cambridge

Peterson CH, Estes JA (2001) Conservation and management of marine communities. In: Bertness MD, Gaines SD, Hay, ME (eds) Marine community ecology. Sinauer, Sunderland, MA, p 469-507

Peterson CH, Kneib RT, Manen C-A (2003) Scaling restoration actions in the marine environment to meet quantitative targets of enhanced ecosystem services. Mar Ecol Prog Ser 264: 173-175 (in this Theme Section)

Phillips BF, Evans LH (1997) Aquaculture and stock enhancement of lobsters: report from a workshop. Mar Freshw Res 48:899-902

Polacheck T, Hilborn R, Punt AE (1993) Fitting surplus production models: comparing methods and measuring uncertainty. Can J Fish Aquat Sci 50:2597-2607

Powers SP, Grabowski JH, Peterson CH, Lindberg WJ (2003) Estimating enhancement of fish production by offshore artificial reefs: uncertainty exhibited by divergent scenarios. Mar Ecol Prog Ser 264:265-277 (in this Theme Section)

Prager MH (1994) A suite of extensions to a non-equilibrium surplus-production model. Fish Bull 92:374-389

Editorial responsibility: Charles Peterson (Contributing Editor), Morehead City, North Carolina, USA
Rago PJ (1984) Production foregone: an alternative method for assessing the consequences of fish entrainment and impingement losses at power plants and other water intakes. Ecol Model 24:79-111

Ricker WE (1975) Computation and interpretation of biological statistics of fish populations. Bull Fish Res Board Can 191:1-382

Russell H (1980) The determination of growth rates for American lobsters. Can Tech Rep Fish Aquat Sci 932. In: Anthony VC, Caddy JF (eds) Proc Canada-US Workshop Status of Assessment Science for NW Atlantic Lobster (Homarus americanus) Stocks. Can Tech Rep Fish Aquat Sci No 932:141-150

Scarratt DJ (1964) Abundance and distribution of lobster larvae (Homarus americanus) in Northumberland Strait. J Fish Res Board Can 21:661-680

Scarratt DJ (1968) An artificial reef for lobsters. J Fish Res Board Can 25:2683-2690

Sheehy DJ (1976) Utilization of artificial shelters by the American lobster (Homarus americanus). J Fish Res Board Can 33:1615-1622

Spanier E (1994) What are the characteristics of a good artificial reef for lobsters? Crustaceana 67:173-186

Stasko AB (1980) Lobster larval surveys in Canada. In: Anthony VC, Caddy JF (eds) Proc Canada-US Workshop Status of Assessment Science for NW Atlantic Lobster (Homarus americanus) Stocks. Can Tech Rep Fish Aquat Sci No 932:141-150

Wahle RA (1993) Recruitment to American lobster populations along an estuarine gradient. Estuaries 16:731-738

Wahle RA, Incze LS (1997) Pre- and post-settlement processes in recruitment of the American lobster, Homarus americanus. J Exp Mar Biol Ecol 217:179-207

Wahle RA, Steneck RS (1991) Recruitment habitats and nursery grounds of the American lobster (Homarus americanus Milne Edwards): a demographic bottleneck? Mar Ecol Prog Ser 69:231-243

Wahle RA, Steneck RS (1992) Habitat restrictions in early benthic life: experiments on habitat selection and in situ predation with the American lobster. J Exp Mar Biol Ecol 157:91-114

Wainwright TC, Armstrong DA, Dinnel PA, Orensanz JM, McGraw KA (1992) Predicting effects of dredging on a crab population: an equivalent adult approach. Fish Bull 90:171-182

Young TP (2000) Restoration ecology and conservation biology. Biol Conserv 92:73-83

Submitted: February 10, 2003; Accepted: October 26, 2003 Proofs received from author(s): December 9, 2003 